(92015, Elsevier. Licensed under the Creative Commons AttributionNonCommercial-NoDerivatives 4.0 International http://creativecommons.org/ about/downloads 


\title{
Characterising Mode I/Mode II Fatigue Delamination Growth in Unidirectional Fibre Reinforced Polymer Laminates
}

\begin{abstract}
O. Al-Khudairi ${ }^{1}$, H. Hadavinia ${ }^{1 *}$, A. Waggott ${ }^{2}$, E. Lewis ${ }^{1}$, C. Little $^{2}$
${ }^{1}$ School of Mechanical \& Automotive Engineering, Kingston University London, UK

${ }^{2}$ The National Renewable Energy Centre (NaREC), Blyth, Northumberland, UK

\section{Abstract}

In this paper, fatigue life estimation for delamination growth of laminated fibre reinforced polymer (FRP) composite structures in mode I and mode II based on fracture mechanics is presented. The proposed method was applied to delamination of glass/epoxy laminated composite. Both the threshold energy release rate $\left(G_{t h}\right)$ and the delamination propagation based on Paris' law were studied. The double cantilever beam (DCB) specimen for mode I and 3 points End-Notched Flexure (3ENF) specimen for mode II were used for monotonic fracture tests and the resistance $G_{I R}$ and $G_{I I R}$ as a function of delamination length were determined. For DCB tests, the fatigue onset life test was conducted and the threshold energy release rate, $G_{I t h}$, was found for the subcritical region. Constant amplitude, displacement controlled cyclic fatigue test for both modes was conducted and the delamination crack growth rate $(d a / d N)$ as a function of maximum cyclic energy release rate $G_{\text {Imax }}$ and $G_{\text {IImax }}$ for DCB and 3ENF specimens were determined, respectively. From curve fitting to the experimental data, the Paris' law material constants $C$ and $m$ for mode I and mode II were obtained. Finally, the SEM fractography studies of delaminated surfaces of 3ENF static and fatigued specimens have been done and the different features observed on these surfaces were discussed.
\end{abstract}

Keywords- Fatigue; Composite laminate; Delamination; Fractography

\footnotetext{
* Corresponding author: Dr H Hadavinia, email: h.hadavinia@kingston.ac.uk ; Tel: +44 2084174864
} 


\section{Introduction}

Fibre reinforced polymer (FRP) composites have a high specific strength, high specific modulus, low weight and low cost relative to the metals. As a result, FRPs are the preferred material for application in many advanced structures when the weight, strength, durability and cost are major concerns. Among FRPs, glass fibre reinforced plastic (GFRP) has lowest cost and for this reason it is used extensively in horizontal axis wind turbine (HAWT) blades. However, these materials are susceptible to delamination by separation of the plies in the low resistance thin resin-rich interface between adjacent layers particularly under compressive buckling load caused under cyclic loading. The out-of-plane stresses, which naturally cause delamination, occur at many types of structural details such as ply drops, skin-stiffener intersections, sandwich panel, free edge, and trailing edge areas, near geometric discontinuities such as holes, cut-outs, flanges, stiffener terminations, bonded and bolted joints (see Figure 1). All of these locations have potential to promote delamination initiation [1]. Other causes of delamination are the existence of contaminated fibres during the manufacturing process, insufficient wetting of fibres, curing shrinkage of the resin, and out-of-plane impact.

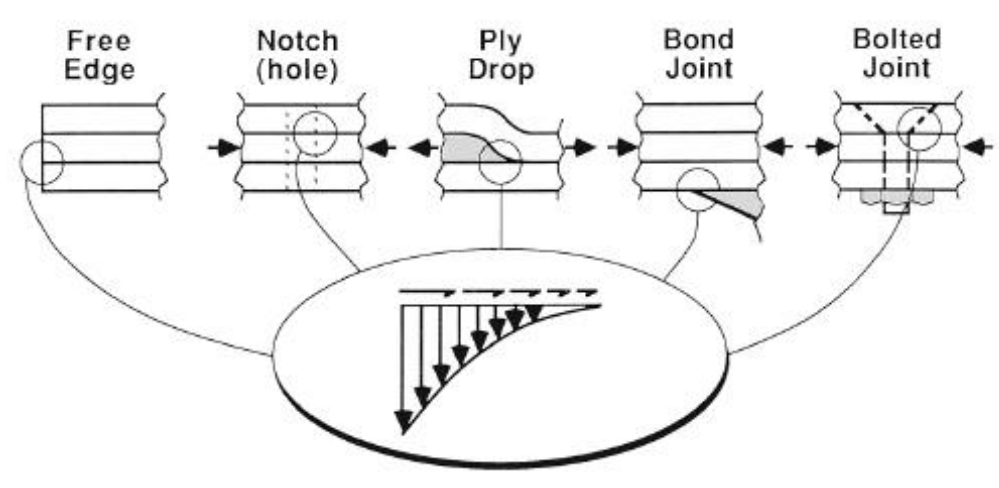

Fig. 1. Common structural elements which generate interlaminar stress concentrations [1].

Characterisation of delamination toughness in mode I and mode II are necessary in advanced structural design. For mode I and mode II loading, quasi-static monotonic delamination testing standards have been developed using Double Cantilever Beam (DCB) and 3 points End-Notched Flexure (3ENF) specimens. Many publications under quasi-static monotonic loading for both modes are available. Williams [2] used beam theory to derive 
the energy release rate from the local values of bending moments and loads in a cracked laminate. Further, Williams [3] extended his work to take into account the effect of arm shortening due to large displacements during crack growth. In their seminal work, Hashemi et al. [4] discussed the methods for analysing the DCB, ELS, and ENF fracture mechanics experimental data. Wang and Williams [5] used a correction factor for the crack length to modify the compliance and SERR expressions for ENF and ELS mode II fracture toughness tests. However, until now no standard has been developed for mode I and mode II delamination under cyclic loading. In the following, a review of some of the published works on DCB and ENF delamination under cyclic loading are presented. From this review the common testing conditions such as specimen size, the frequency range and R-ratio for both specimens under cyclic loading were established.

For mode I DCB specimen Shivakumar et al. [6] reported the total fatigue life model for woven-roving glass fibre/vinyl ester in mode I loading. The study included delamination growth in subcritical, linear and final fracture regions. The tests were conducted under displacement control, at a frequency range between $1-4 \mathrm{~Hz}$ and $\mathrm{R}=0.1$.

Hojo et al. [7] reported on delamination of CFRP prepreg under fatigue loading in mode I, using DCB test specimens. They used two CFRP prepreg laminates $[0]_{16}$ of Toray $\mathrm{T} 800 \mathrm{H} / 3900-2$ and $[0]_{24}$ of Toho UT500/111. Tests were conducted at R-ratios of $0.1,0.2$ and 0.5 at a frequency of $10 \mathrm{~Hz}$. Specimen dimensions of length $140 \mathrm{~mm}$, width $20 \mathrm{~mm}$, thickness $3 \mathrm{~mm}$ and pre-crack 20-25mm were used. In further mode I work, Hojo et al. [8] looked at DCB fatigue delamination of Z-reinforced CFRP laminates. CFRP cross-ply laminates were stitched with a high-strength, intermediate-modulus dry carbon fibre fabric. Test specimens stacking sequence were $\left[0 / 90_{2} / 0\right]_{s}$ and DCB specimen dimensions of length $150 \mathrm{~mm}$, width $10 \mathrm{~mm}$, thickness $1.8 \mathrm{~mm}$ and pre-crack $35 \mathrm{~mm}$ were used. In the fatigue tests, the R-ratio has been set to 0.1 and 0.5 , at a frequency of $10 \mathrm{~Hz}$. They reported stitching laminates in z-direction have 3.4-5.0 times higher fatigue threshold than without stitching. Pegorin et al. [9] showed that z-pinning is more effective at resisting mode I than mode II fatigue cracking.

Arai et al. [10] studied delamination of unidirectional CFRP prepreg under cyclic loading in mode I, using DCB specimens with dimensions of length $150 \mathrm{~mm}$, width $20 \mathrm{~mm}$, thickness 
$3.28-3.36 \mathrm{~mm}$ and pre-crack length of $40 \mathrm{~mm}$. They reported an increase of $50 \%$ to the initiation delamination fracture toughness and $20 \%$ increase at the final fracture toughness when comparing the CFRP results to CFRP with carbon nano-fibre interlayer.

Coronado et al. [11] studied influences of temperature on delamination in CFRP under cyclic loading. The mode I monotonic and cyclic loading tests were performed under operating temperatures of $90,50,20,0,-30$ and $-60{ }^{\circ} \mathrm{C}$. They concluded during the initiation of fatigue delamination, $G_{I C \max }$ increased as the temperature rose, but significantly decreased after the crack initiation. The crack growth rates at $-30^{\circ} \mathrm{C}$ and $-60^{\circ} \mathrm{C}$ were significantly higher than those at higher temperature, showing the matrix has inherited brittle behaviour.

For mode II ENF specimen, Hojo et al. [12] studied CFRP laminates under mode II fatigue loading. They tested CFRP unidirectional laminates $[0]_{24}$ and with $50 \mu \mathrm{m}$-epoxy-interleaved laminates $\left[0_{12} /\right.$ film $\left./ 0_{12}\right]$. Three point End Notched Flexure (3ENF) specimens with dimensions length $160 \mathrm{~mm}$, span $100 \mathrm{~mm}$, width $10 \mathrm{~mm}$, thickness $3 \mathrm{~mm}$ and pre-crack $25 \mathrm{~mm}$ were used. Tests performed at $\mathrm{R}$ ratio of 0.1 and 0.5 at a frequency of $10 \mathrm{~Hz}$. They showed initiation interlaminar fracture toughness of $50 \mu \mathrm{m}$-epoxy-interleaved laminate is 1.6 times higher than the base CFRP and 3.5 times higher in the propagation values.

Shindo et al. [13] studied the cryogenic delamination growth behaviour in woven GFRP laminates under Mode II fatigue loading using 4ENF specimens at a frequency of $2 \mathrm{~Hz}$ at $\mathrm{R}$ ratio of 0.1 . The test is conducted at three different temperatures: room temperature, liquid nitrogen (77K) and liquid helium (4K). The 4ENF specimens with dimensions of length $90 \mathrm{~mm}$, width $20 \mathrm{~mm}$, thickness $3.65 \mathrm{~mm}$, pre-crack $30 \mathrm{~mm}$ were used. They concluded that delamination growth rate is lower at low temperatures and when decreasing the temperature the threshold energy release rate becomes larger. They reported $\Delta G_{\text {IIth }}$ values are about one-third of the $G_{I I C}$ values at the different temperatures. Asp et al. [14] was observed similar ratio between the static and fatigue tests results on CFRP composites at room temperature. They reported the threshold values for delamination growth in fatigue are lower than the fracture toughness $\left(G_{C}\right)$. They reported the reduction is greatest for the ENF test for which $\Delta G_{I I t h}$ is only $10 \%$ of $G_{C}$ and the threshold values for the MMB and DCB tests are also much lower than the fracture toughness, at $15 \%$ and $23 \%$, respectively. 
Landry et al. [15] explored CFRP material under mode II fatigue loading at a frequency of $1 \mathrm{~Hz}$ at $\mathrm{R}=0.2$. They investigated the effect of exposing the laminate to water, hydraulic fluid and deicing fluid experimentally and numerically. The specimens with dimensions of length $94 \mathrm{~mm}$, width $20 \mathrm{~mm}$, thickness $2.25 \mathrm{~mm}$ and $3 \mathrm{~mm}$ and pre-crack length $35.5 \mathrm{~mm}$ were used. They concluded that the results based on crack length measured using compliance calibration method are good and can be obtained with minimum number of specimens. The delamination toughness is adversely affected on those specimens that are exposed to fluids. In quasi-static monotonic testing delamination toughness reduced by $20-25 \%$ in water and deicing immersion, but only $4 \%$ reduction in hydraulic fluid.

Fernandez et al. [16] investigated CFRP laminates under mode II fatigue loading. The $[0]_{18}$ 3ENF specimens with dimensions of length $90 \mathrm{~mm}$, width $25 \mathrm{~mm}$, thickness $2.7 \mathrm{~mm}$, pre-crack length $45 \mathrm{~mm}$ were used. The tests were carried out at a frequency of $4 \mathrm{~Hz}$ and $\mathrm{R}=0.1$. They used Paris' law to establish the relationship between the fatigue crack growth rate and the applied strain energy release rate range.

The general form of Paris' law based on fracture mechanics for delamination growth as depicted in region II of Figure 2 is:

$$
\frac{d a}{d N}=C f(G)^{m}
$$

In the literature many versions of Eq. (1) has been proposed to take into account effects such as R-ratio, mode mixity, threshold and fast fracture regions. Two important points about the form of $f(G)$ in Paris's law Eq. (1) should be discussed. Firstly whether we have to choose $f(G)=G_{\max }$ or $f(G)=\Delta G=G_{\max }-G_{\min }$, and more recently $f(G)=\Delta \sqrt{G}$ where $\Delta \sqrt{G}=\left(\sqrt{G_{\max }}-\sqrt{G_{\min }}\right)^{2}$ [17]. Secondly what parameter is suitable for normalisation?

Until now no general consensus has been agreed by the research community on whether Eq. (1) should be a function of $G_{\max }$ or a form of $\Delta G$. Various versions of Paris' law can be found in the literature. Both $f(G)=G_{\max }$ and $f(G)=\Delta G$ have been successfully correlated with delamination growth by many researchers. The function $f(G)=G_{\max }$ has been used in many studies such as [7], [8], [18], [19], while $f(G)=\Delta G$ has been used in 
other researches such as [20] [21] [22]. Little difference has been reported when using either $f(G)=G_{\max }$ or $f(G)=\Delta G$. Wilkins et al. [23] discussed $G_{\max } / G_{\min }$ is proportional to load ratio $R$ and effectively $G_{\max }$ and $\Delta G$ will be very close to each other.

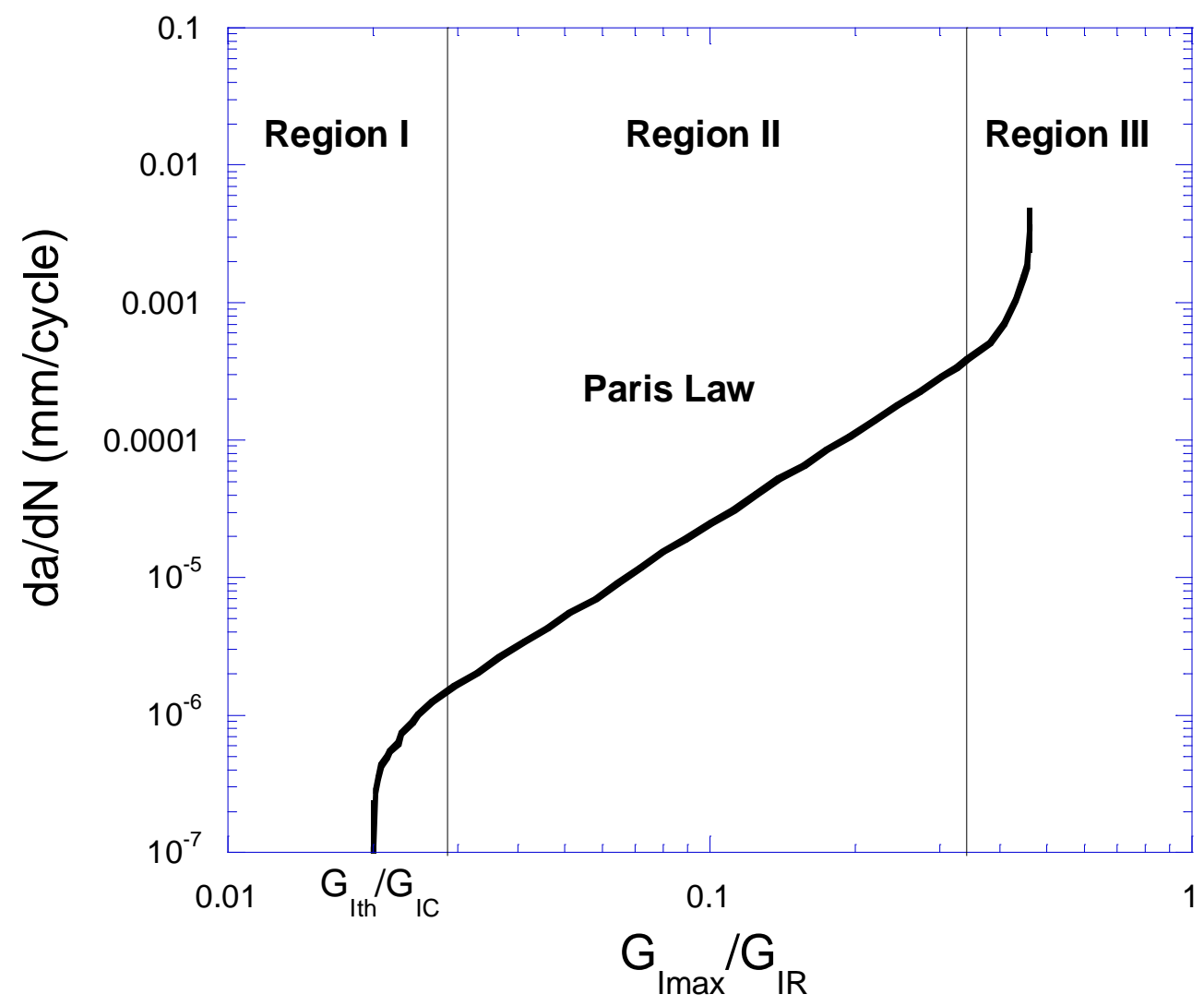

Fig. 2. Schematic curve of fatigue crack propagation.

Recently Alderliesten [17] [24] and Yao et al. [25] reported that the intent in using $\Delta G=G_{\max }-G_{\min }$ in analogy to $\Delta K$ as a fracture mechanics parameter for delamination growth is not incorrect. They argued by using $\Delta G$, researchers have been attempting to introduce the similitude principle used for metal crack growth into their characterization of fatigue delamination growth in laminated composites. This definition of the strain energy release rate range implies similitude based on a specific combination of cyclic load range and mean (or peak) load without any physical basis. They showed that for a LEFM description of fatigue fracture using strain energy release rate and the principle of superposition, the strain energy release rate range, $\Delta G$, should be defined using $\Delta \sqrt{G}=$ $\left(\sqrt{G_{\max }}-\sqrt{G_{\min }}\right)^{2}$ removing the mean load dependency present when using $\Delta G=$ $G_{\max }-G_{\min }$ 
Jones et al. [26] showed that crack growth in a range of nano-composites can be reasonably represented by a variant of the Hartman-Schijve equation in the form of:

$$
\frac{d a}{d N}=D\left(\left(\Delta \sqrt{G_{\max }}-B\right) / \sqrt{\left(1-\sqrt{G_{\max }} / A\right)}\right)^{\beta}
$$

where the values of $A, B$ and $D$ are constant parameters that are used for data fitting in the entire range. They showed Eq. (2) is applicable to delamination crack growth in both Modes I and Mode II in composites and to the environmental degradation of epoxies adhesive bonds. Jones et al. [26] reported when the delamination crack growth in FRP composites expressed in this form, the exponent of this variant of delamination crack growth is approximately $\beta=2$ which is considerably lower than the exponent $m$ in Paris law Eq. (1). They mentioned the large exponent $m$ will cause small uncertainties in the applied load leads to large uncertainties in the predicted delamination growth rate.

With regard to normalising the Paris' law Eq. (1), many researchers adopted the form of $f(G)=\frac{G_{\max }}{G_{c}}$ or $f(G)=\frac{\Delta G}{G_{c}}$ [27] [28] [29] and others the form of $f(G)=\frac{G_{\max }}{G_{R}}$ [6] [30] [31] [32] [33].

In the classical fracture mechanics and for a given mode mix and environmental conditions, $G_{C}$ is assumed to be constant. The quantity $G / G_{C}$ is scaling of the crack-driving force relative to the material's resistance. In this way the resistance to fatigue delamination is scaled relative to the static fracture toughness [34]. However, in some other works, e.g. [12] [35] [36] the assumption of correlation of resistance between static delamination growth and fatigue delamination growth has been questioned.

In unidirectional FRP composites when characterising $0 / 0$ ply interface, during delamination growth the plies tend to nest and multiple damage mechanisms, such as fibre bridging and matrix cracking occur which increase the apparent fracture toughness of the interface [6] [37] [38]. Therefore, it is suggested that $G_{R}(a)$ determined from a quasi-static delamination test is a better phenomenological parameter for normalisation as it combines many different effect that change resistance into one value (i.e. an R-curve). Hence, normalisation of the SERR by $G_{R}(a)$ rather than $G_{C}$ in the form of $f(G)=\frac{G_{\max }}{G_{R}}$, is suggested as $G_{R}(a)$ 
represents the changing resistance to delamination growth over the course of a fatigue loading history [6] [30] [31] [32] [33] [39]. $G_{R}(a)$ is determined from the static R-curve at the delamination length reached during the fatigue testing. Note that unlike $G_{C}$, the $G_{R}(a)$ curve is specific as it depends on the material, stacking sequence, and other forms of mechanisms involved.

One of the benefits of normalisation by $G_{R}$ is to reduce the spread in the delamination growth data. However, Murri [31] reported the magnitude of fibre bridging during fatigue loading is probably lower than during quasi-static loading. The use of the R-curve implies that the quasi-static delamination mechanism is the same as the fatigue delamination mechanism and therefore the resistance to quasi-static growth also determines the resistance to fatigue growth. Recent fractographic evidence [40] does not fully support this.

It should be noted that a model to present the full range of sigmoidal shape of delamination growth model in fatigue cracking process including all three regions as shown in Figure 2 has been applied by many researchers, e.g. [41] [42] [43], in the form of:

$$
\frac{d a}{d N}=C\left(G_{\max }\right)^{m} \frac{\left[1-\left(\frac{G_{t h}}{G_{\max }}\right)^{n_{1}}\right]}{\left[1-\left(\frac{G_{\max }}{G_{C}}\right)^{n_{2}}\right]}
$$

Where parameters $C, m, n_{1}$ and $n_{2}$ are found from fitting the full spectrum of fatigue test data.

In conclusion as the fatigue life estimation based on Paris' law has a phenomenological macroscopic empirical nature and Paris law is an empirical relation rather than a constitutive material law, as long as the relationship between $d a / d N$ and a form of SERR describe accurately the crack growth, any form of SERR is acceptable. This will be true until a relationship based on a true physical nature of the fatigue crack propagation based on micromechanics damage develops in the future. As mentioned by George E. P. Box [44] "Essentially, all models are wrong, but some are useful". It should be emphasised that by using $f(G)=\frac{G_{\max }}{G_{R}}$ in Eq. (1), the Paris' law coefficient $m$ has no unit and $C$ is the speed of crack propagation when $G_{\max }=G_{R}$ at fast fracture. 
In this paper, fatigue life estimation for delamination growth of laminated fibre reinforced polymer (FRP) composite structures in mode I and mode II based on fracture mechanics will be presented. The proposed method was applied to delamination of glass/epoxy laminated composite. Both the threshold energy release rate $\left(G_{I t h}\right)$ and the delamination propagation based on Paris' law were studied. Monotonic tests of DCB specimen in mode I and 3ENF specimen in mode II were conducted according to the ASTM: D5528 and ASTM: WK22949 standards and the resistance $G_{I R}$ and $G_{I I R}$ as a function of delamination length were established. For DCB tests, the fatigue onset life test was performed and the threshold energy release rate, $G_{I t h}$, was found.

Constant amplitude, displacement controlled cyclic fatigue tests for both modes was conducted and the delamination crack growth rates $(\mathrm{da} / \mathrm{dN})$ as a function of maximum cyclic energy release rate $G_{I \max }$ and $G_{\text {IImax }}$ for DCB and 3ENF specimens were determined, respectively. From curve fitting to the experimental data, the Paris' law material constants $C$ and $m$ for mode I and mode II were obtained. Finally, the SEM fractography studies of delaminated surfaces of ENF static and fatigue specimens have been done and the different features observed on these surfaces were discussed.

\section{Material properties and specimens preparation}

The UD prepreg E-glass fibre/E722 epoxy matrix material supplied by TenCate Ltd. was used for preparation of all specimens in this work. For analysis of delamination, mechanical properties of the GFRP are required. The mechanical properties of the FRP composite such as Young's modulus, shear modulus, etc. were obtained by performing $0^{\circ}$ and $90^{\circ}$ tensile and compression and $\pm 45^{\circ}$ shear tests according to the standards. The tests results are summarised in Table 1. 
Table 1. Mechanical properties of GFRP laminate measured from experiments.

\begin{tabular}{|ll|}
\hline Longitudinal Young's modulus $\mathrm{E}_{11}(\mathrm{GPa})$ & \\
\hline Transverse Young's modulus $\mathrm{E}_{22}(\mathrm{GPa})$ & $38.9 \pm 0.2$ \\
\hline Shear Modulus $\mathrm{G}_{12}(\mathrm{GPa})$ & $13.0 \pm 1.5$ \\
\hline Poisson's ratio u12 & $5.0 \pm 0.2$ \\
\hline Tensile strength in fibre direction Xt (MPa) & $0.24 \pm 0.01$ \\
\hline Tensile strength normal to fibre direction $\mathrm{Yt}(\mathrm{MPa})$ & $619 \pm 6$ \\
\hline Compressive strength in fibre direction $\mathrm{Xc}(\mathrm{MPa})$ & $69 \pm 6$ \\
\hline Compressive strength normal to fibre direction $\mathrm{Yc}(\mathrm{MPa})$ & $230 \pm 15$ \\
\hline Shear strength S (MPa) & $180 \pm 10$ \\
\hline Fibre volume fraction & $47 \pm 1$ \\
\hline
\end{tabular}

The lay-up of DCB and 3ENF specimens for static and fatigue testing were $\left[0_{15} / / 0_{15}\right]$, where the sign // refers to the plane of the artificial starter delamination from one end. The DCB and ENF specimens have a total length of $180 \mathrm{~mm}$ and $160 \mathrm{~mm}$, respectively, both with a width of $b=20 \mathrm{~mm}$ and beam thickness of $8.5 \mathrm{~mm}$ (The details of specimens are shown in Figure 3 ). The specimens were manufactured by hand lay-up and a vacuum bagging technique. A PTFE release film with thickness of $20 \mu \mathrm{m}$ was used as a crack starter of length $55 \mathrm{~mm}$ from one end of the beam for all specimens. After curing, the specimens were returned to room temperature. For DCB specimen epoxy adhesive ESP110 with thickness of $0.5 \mathrm{~mm}$ was applied to the steel end tabs of $10 \times 10 \times 20 \mathrm{~mm}$ with a hole of $5 \mathrm{~mm}$ drilled at the centre. Next the end tabs were clamped to the beam on the pre-crack side, returned back to the oven and cured for $60 \mathrm{~min}$ at $120^{\circ} \mathrm{C}$. Finally, the edges of both DCB and ENF specimens covered with white correction fluid and lines were marked at the edges from the crack tip at every $1 \mathrm{~mm}$. During the tests, the crack length was observed and recorded using a travelling microscope. All tests were performed at ambient conditions. 


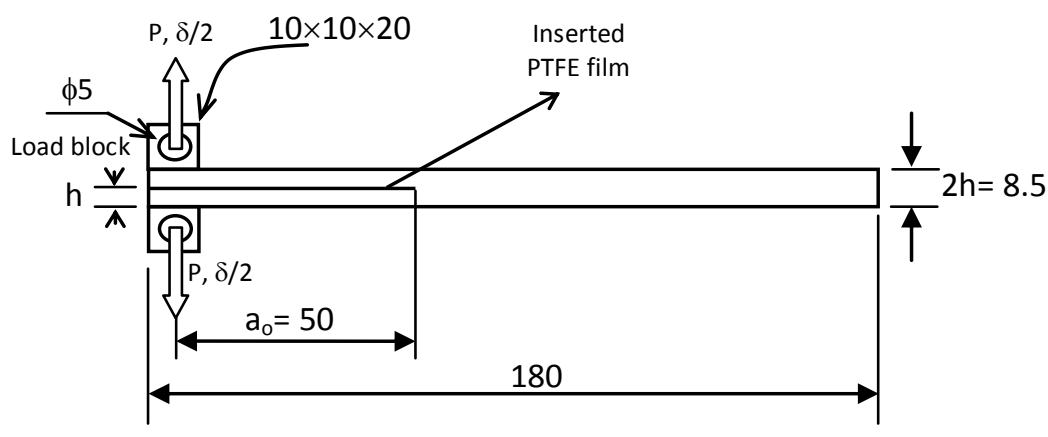

(a) DCB specimen

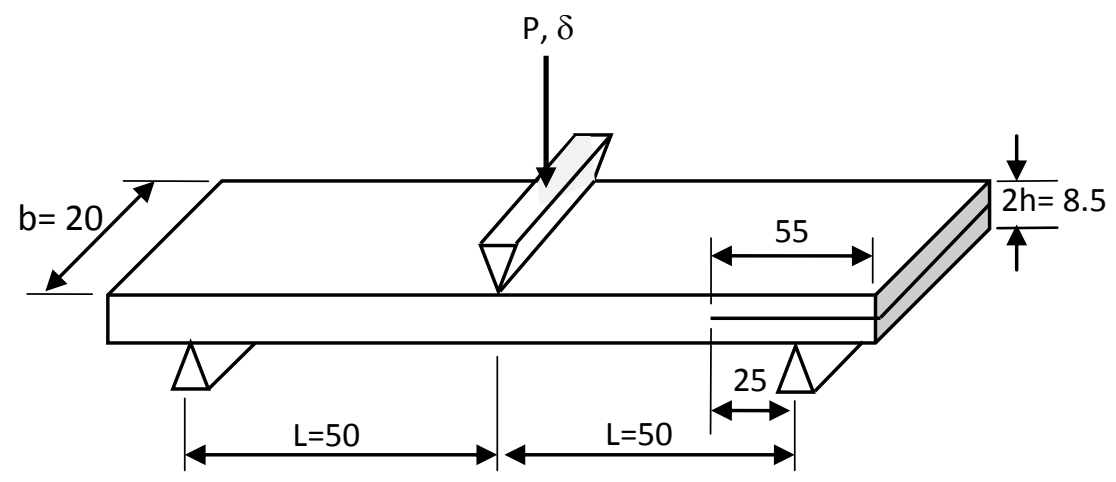

(b) 3ENF specimen

Fig. 3. Dimensions of (a) DCB and (b) 3ENF test specimens. All dimensions are in $\mathrm{mm}$.

\section{Mode I fatigue delamination growth in GFRP laminates}

Delamination is a major weakness of laminated composite materials and understanding the resistance of the FRP materials to interlaminar fracture under cyclic loading is essential for establishing guidelines for allowable and damage tolerance design in the structures.

Fracture mechanics based models for prediction of fatigue lifetime and estimation of the remaining life of metallic components are well established. In FRP composite also delamination growth models are required for predicting fatigue lifetime and establishing suitable inspection intervals. In a structure when delamination is detected, repair should have been done long before the critical length or the stress at the crack tip exceeds the residual strength of the component. Similar to metals, in FRP composite materials fatigue delamination growth follows a sigmoidal curve when $\log \left(\frac{d a}{d N}\right)$ plotted against $\log \left(\frac{G_{I \max }}{G_{I R}}\right)$ as shown schematically in Figure 2. Here $G_{\text {Imax }}$ is the strain energy release rate at maximum 
stress and $G_{I R}$ is the mode I delamination instantaneous resistance. This curve consists of three regions- Region I covers the threshold. Below the fatigue threshold, $G_{I t h}$, the crack growth is normally less than $10^{-7} \mathrm{~mm} /$ cycle (see ASTM: E 647). Region II is the stable growth. This region emerges after the fatigue threshold limit and continues up to the delamination fracture toughness of the material. Region II follows the Paris' law equation:

$$
\frac{d a}{d N}=C\left(\frac{G_{I m a x}(a)}{G_{I R}(a)}\right)^{m}
$$

Finally, in Region III the crack propagation becomes unstable and is characterized by its rapid and catastrophic failure. The life of a structure can be estimated by using the entire Paris's law curve.

\subsection{Mode I quasi-static test}

In unidirectional composites laminates, the delamination resistance increases during crack growth due to matrix cracking and fibre bridging due to nesting of the laminates. As discussed in the introduction these effects can be accounted by normalizing the applied load $G_{I m a x}$ by the instantaneous resistance value $G_{I R}$ obtained from a static test. Therefore, determination of $G_{I R}(a)$ for fatigue crack propagation is required.

Quasi-static DCB tests were conducted and initiation fracture toughness $G_{I C}=764 \mathrm{~J} / \mathrm{m}^{2}$ and variation of the critical energy release rate $G_{I R}$ as a function of crack length were determined. A power law equation was fitted to the experimental data as shown in Figure 4(b). The resulting resistance equation for DCB specimens is:

$$
G_{I R}=G_{I C}+20.2\left(a-a_{0}\right)^{0.64}
$$

Where $a$ is the instantaneous crack length and $a_{0}$ is the initial crack length both measured from tip of the crack to the load line. The strain energy release rate (SERR) was calculated using the modified beam theory (MBT):

$$
G_{I}=\frac{3 P \delta}{2 b(a+|\Delta|)}
$$

In the above $P$ is the applied load, $\delta$ is load line displacement, and $b$ is the specimen width. The delamination length correction parameter $|\Delta|=2.293 \mathrm{~mm}$ was determined from the 
plot of the specimen compliance and delamination crack length data from quasi-static test (For details see [3] , [45] and [46]).

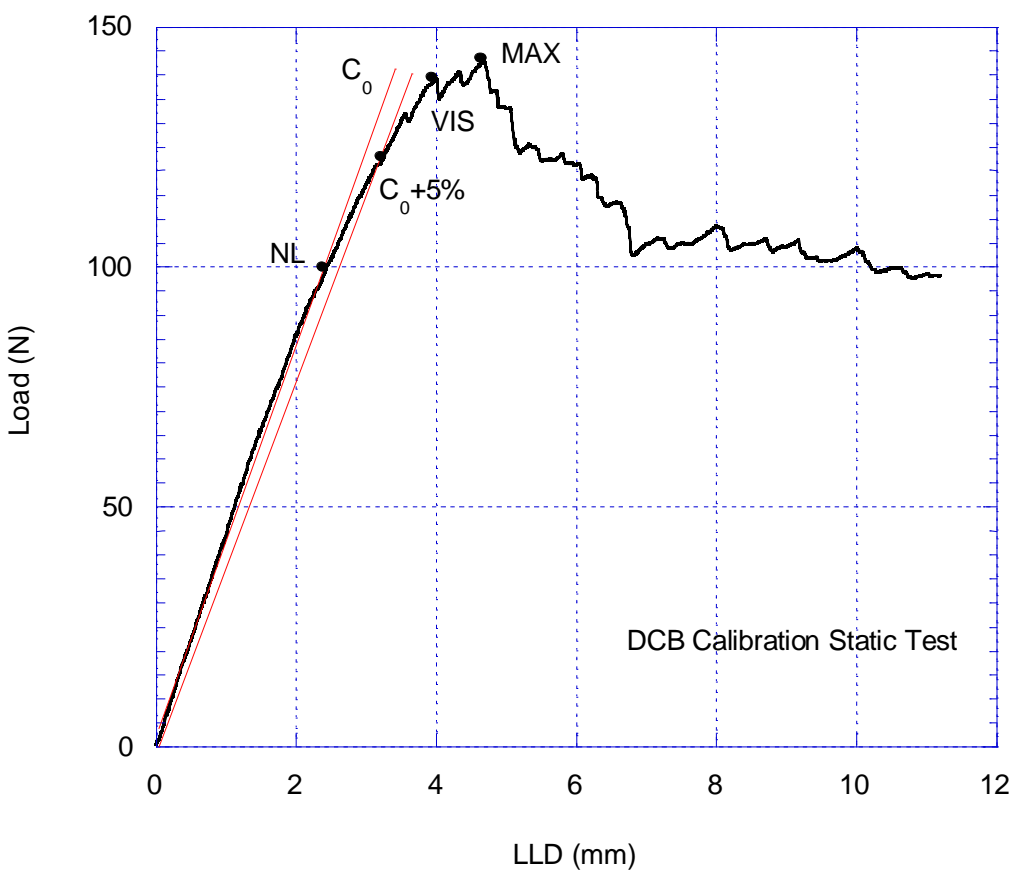

(a)

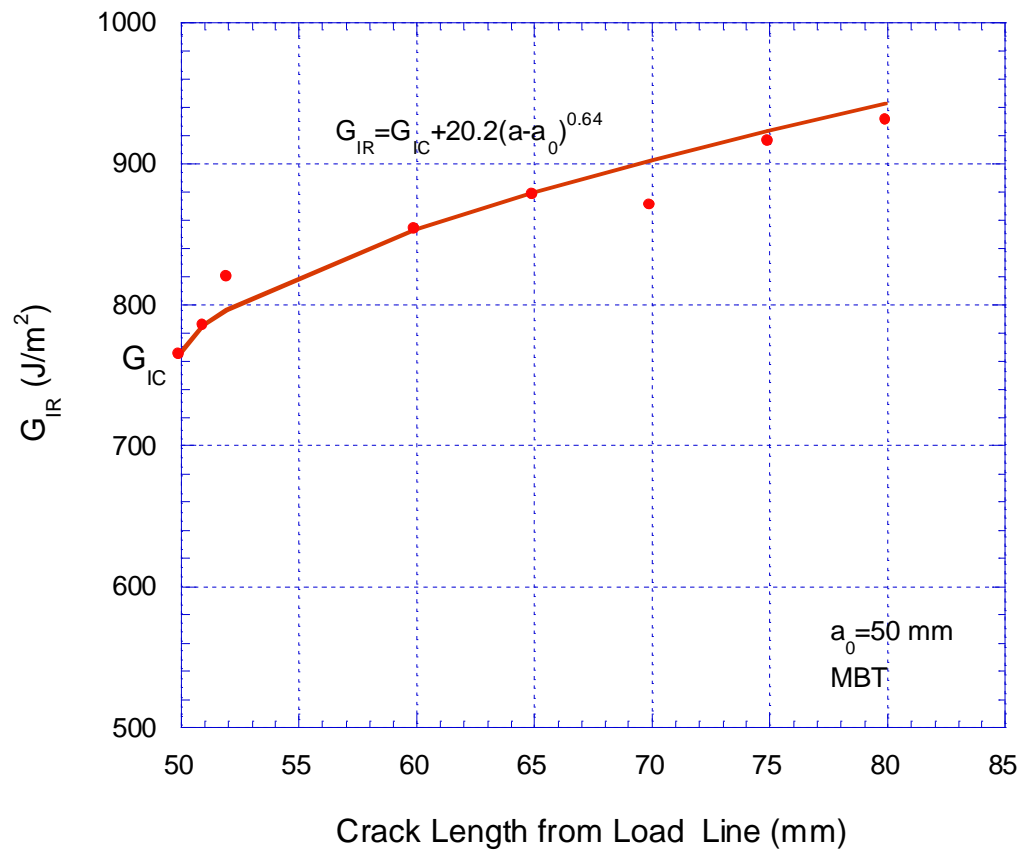

(b)

Fig. 4. (a) Load versus load line displacement in DCB test, (b) Energy release rate versus delamination growth length for GFRP laminate in $\left[0_{15} / / 0_{15}\right.$ ] DCB test using MBT method, $\mathrm{G}_{\mathrm{IC}}=764 \mathrm{~J} / \mathrm{m}^{2}$. 


\subsection{Determination of mode I threshold toughness using onset life test}

All fatigue tests were conducted under constant-amplitude tension-tension displacement control at a cyclic load frequency of $5 \mathrm{~Hz}$ with the ratio of minimum to maximum displacement, $\mathrm{R}=\delta_{\min } / \delta_{\max }$, of 0.1 on a Zwick/Roell Amsler $25 \mathrm{kN}$ servo hydraulic fatigue testing machine (see Figure 5). The DCB specimens were connected to the test rig by selfaligning hinges. The corresponding information of load, displacement and number of cycles were stored by the machine software at a rate of 40 samples per cycle in a text file enabling data evaluation after the test.

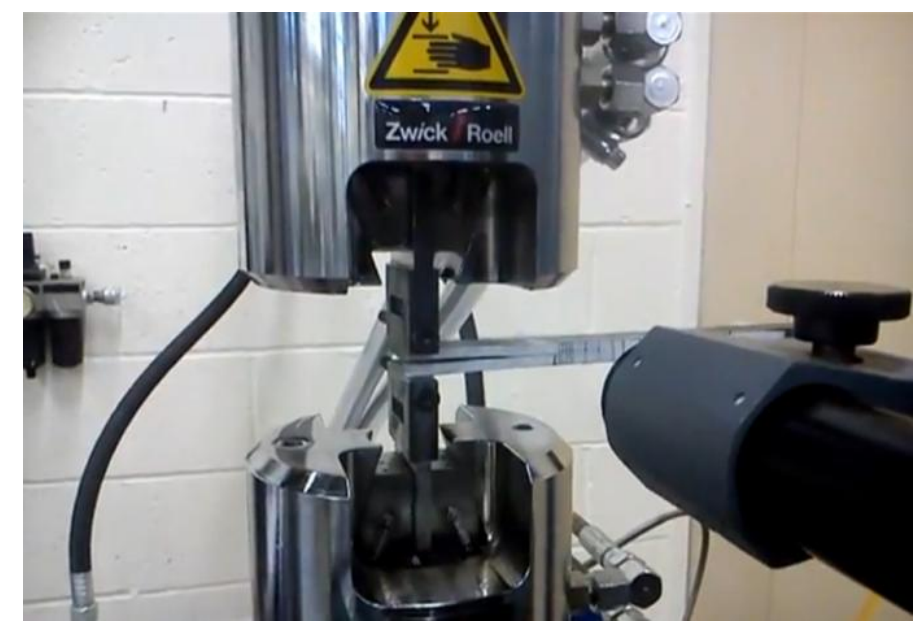

Fig. 5. Mode I fatigue testing of DCB specimen and loading fixture.

The ASTM: D6115 standard recommends two criteria for determining the threshold onset life, namely $1 \%$ and $5 \%$ increase of compliance compared to the compliance at the first cycle $\mathrm{N}=1$ (see Figure 6). The number of cycles measured at $1 \%$ and $5 \%$ increase in compliance has been recorded to determine the initiation threshold. The DCB specimens were used for onset test. In each test $\delta_{\max }$ was chosen to apply a $G_{\max }$ from $20 \%$ to $40 \%$ of $G_{/ C}$ and $\delta_{\min }$ was calculated from $R=0.1$. The tests were terminated after an increase of $5 \%$ to initial compliance was achieved. Some samples were used more than once by choosing a new $\delta_{\max }$ resulting in a different $G_{\max }$ while keeping $\mathrm{R}=0.1$ unchanged.

The delamination threshold fracture toughness $G_{t h}$ can be determined by a curve fit to $G_{\text {Imax }} / G_{I C}$ and number of cycles $N$ measured at $1 \%$ and $5 \%$ increase of compliance from the fatigue onset life test. 


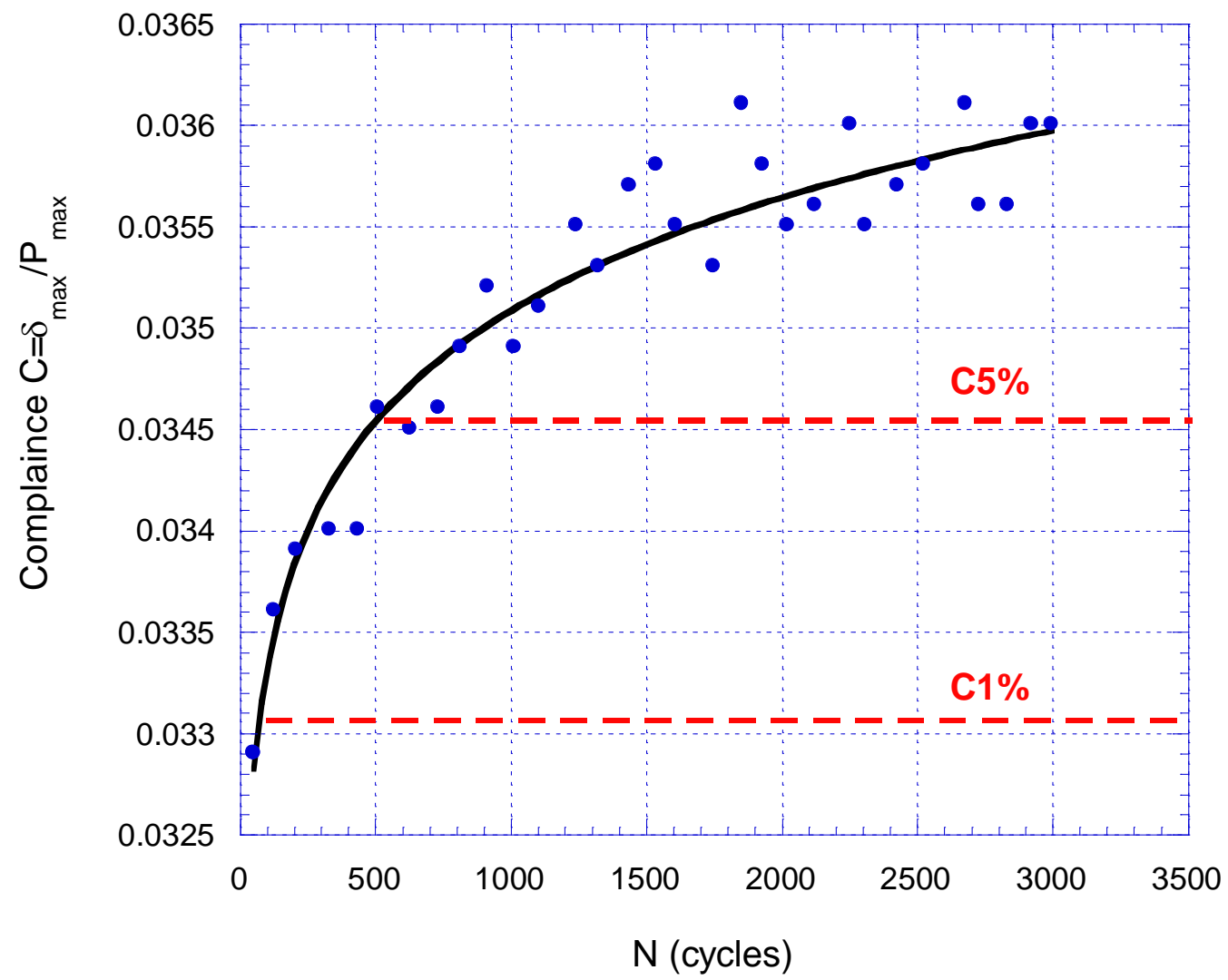

Fig. 6. Compliance versus number of cycles in DCB initiation test together with $1 \%$ and $5 \%$ increase in compliance for loading at $G_{\max }=30 \% G_{C}$.

Figure 7 shows the plot of $G_{I \max } / G_{I C}$ versus $\log N$ for $1 \%$ and $5 \%$ criteria for the data collected from all the tested DCB specimens and the first data point is obtained from the quasi-static test. O'Brien [47] and suggested a linear relationship between $G_{\text {Imax }}$ and $\log N$ data for $10^{0}<\mathrm{N}<10^{6}$ and then he obtained the $G_{t h}$ value from fitted equation calculated at $\mathrm{N}=10^{6}$. For the present study following Shivakumar et al. [6] a power law curve was fitted to the data and the fitted equation (see Figure 7) is:

$$
\frac{G_{I \max }}{G_{I C}}=(\log N+1)^{-0.93}
$$

And they also obtained the threshold SERR value at $\mathrm{N}=10^{6}$.

In the present study the threshold strain energy release rate $\left(G_{t h}\right)$ calculated from Eq. (7) at $\mathrm{N}=10^{7}$ cycles is $G_{t h}=0.15 G_{I C}$. As a result if the applied SERR is less than $15 \%$ of mode I delamination fracture toughness, the speed of crack is very slow and the crack speeds will remain unchanged until 10 million cycles. 


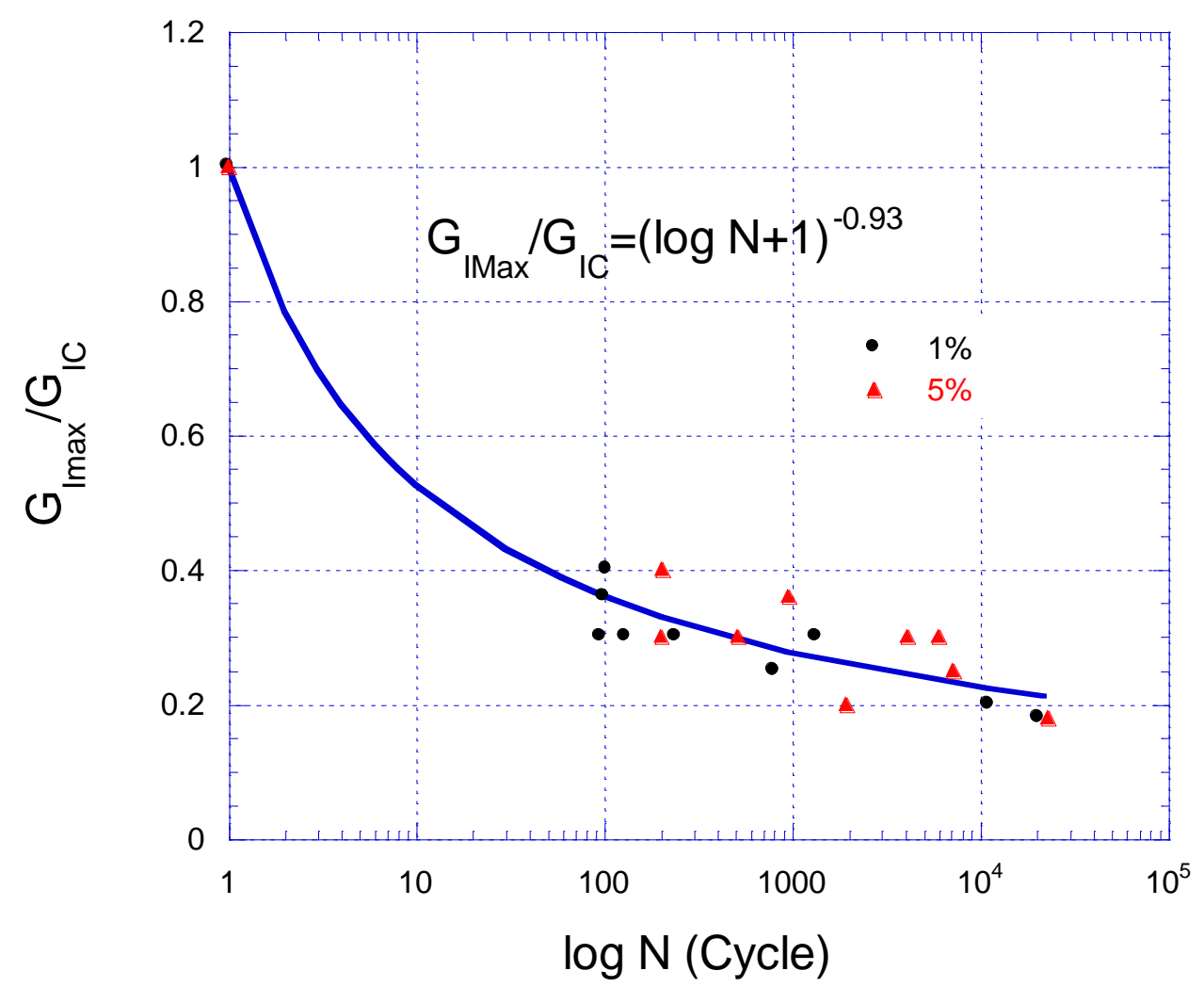

Fig. 7. Variation of onset fatigue life with $G_{I \max } / G_{\mid c}$.

\subsection{Fatigue crack propagation tests in mode I}

The same set-up and three of DCB specimens that were used for fatigue onset life tests were also used in the fatigue propagation tests. All DCB crack propagation tests were conducted with displacement control at a frequency of $5 \mathrm{~Hz}$ and a tension-tension displacement ratio $\mathrm{R}=0.1$. All test specimens were already precracked in onset life tests and for fatigue delamination growth test the new initial delamination lengths were measured and recorded.

Delamination growth rate data was generated by applying the $\delta_{I \max }$ corresponding to $\left(G_{\text {Imax }} / G_{I C}\right)$ between 0.3 and 1 . The fatigue test was run for a predetermined number of cycles. The test was stopped, the travelling microscope was examined to measure the final crack length at the end of the loading cycle and loads and delamination lengths were recorded. When no measurable delamination propagation was observed after some interval, the load has been increased. At the end of each set of $\Delta \mathrm{N}$, the test was stopped and $N, \Delta N, a, \Delta a, P_{I \max }$ and $\delta_{I \max }$ were recorded. From these results, $d a / d N, G_{I \max }$, and $G_{I R}$ were calculated. The $G_{\text {Imax }}$ was calculated using: 


$$
G_{I \max }=\frac{3 P_{\operatorname{Imax}} \delta_{\operatorname{Imax}}}{2 b(a+|\Delta|)}
$$

where $|\Delta|=2.293 \mathrm{~mm}$ was obtained from the quasi-static fracture test. Results of three delamination crack growth tests in DCB specimens are shown in Figure 8.

The test data and the equation are bounded by the limits $G_{I \max } / G_{t h}$ and $G_{I \max } / G_{I C}=1$. The $G_{t h}$ from the onset life test was determined at $0.15 G_{I C}$. From the fitted curve to the propagation data, the Paris' law coefficients for the GFRP for mode I loading were found to be $\mathrm{m}=5.27$ and $\mathrm{C}=4.47 \times 10^{-2}$. Therefore, the $d a / d N$ equation representing region II delamination growth is:

$$
\frac{d a}{d N}=4.47 \times 10^{-2}\left(\frac{G_{\operatorname{Imax}}(a)}{G_{I R}(a)}\right)^{5.27}
$$

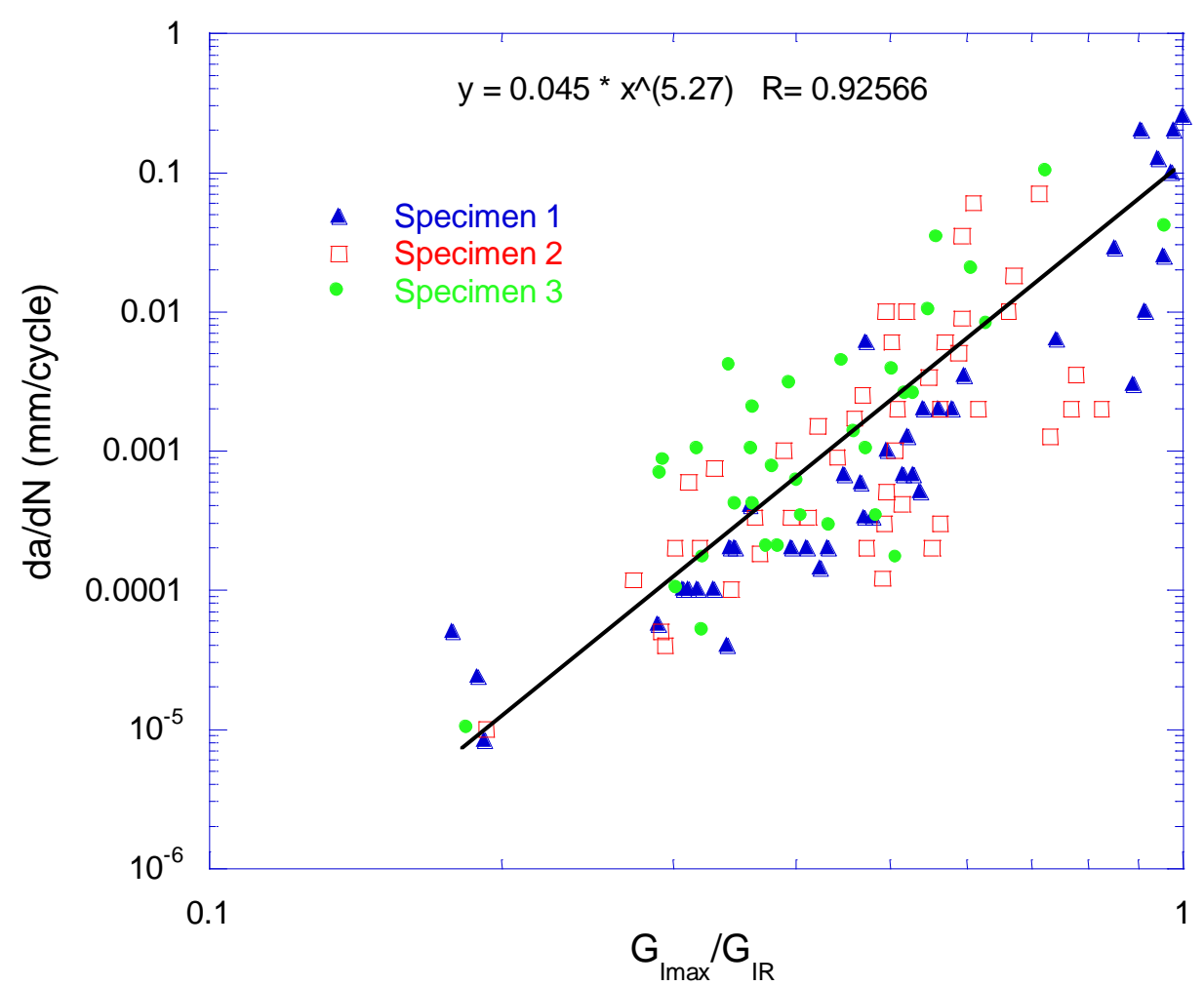

Fig. 8. Crack propagation in DCB specimens.

\section{Mode II fatigue delamination growth in GFRP laminates}

One of the methods for measuring mode II delamination fracture toughness is using 3 points End-Notched Flexure (3ENF) test. The test consisted of a three-point bending specimen with 
a pre-crack that leads to shear loading at the crack tip. Recently the 3ENF test is also used for measuring the behaviour of mode II interlaminar delamination under cyclic loading.

\subsection{Mode II quasi-static test}

As in the case for DCB specimen, there are standards and many publications regarding mode II delamination toughness test of FRP laminates under quasi-static monotonic loading. However, until now no standard has been developed for mode II delamination under cyclic loading. As a consequence of its success in the literature reviewed, in this work the 3ENF test was chosen to perform mode II fatigue crack propagation tests on GFRP laminates (see Figure 9). The analysis is based on the application of Paris' law as a function of energy release rate for mode II loading to characterize fatigue behaviour in this mode.

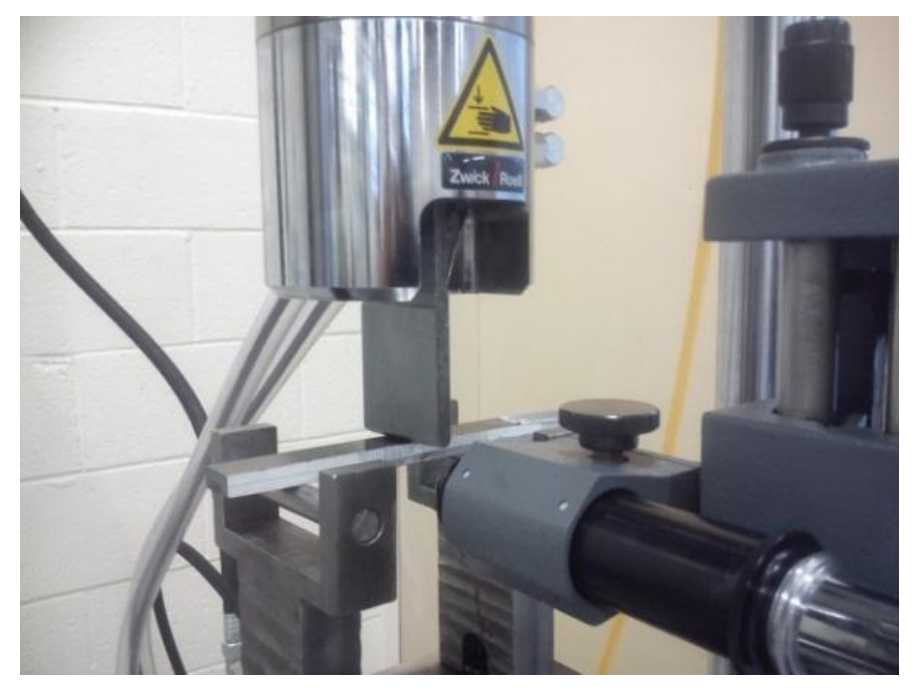

Fig. 9. Mode II Fatigue testing of 3ENF specimen.

As in the case of mode I crack propagation test, quasi-static 3ENF tests were performed to obtain the $G_{I I C}$ at initiation and also the resistance curve $G_{I I R}$ during the crack propagation. Figure 10 shows the results of quasi-static 3ENF test. The onset of the nonlinear part was used to calculate the conservative initiation mode II delamination fracture toughness value. 


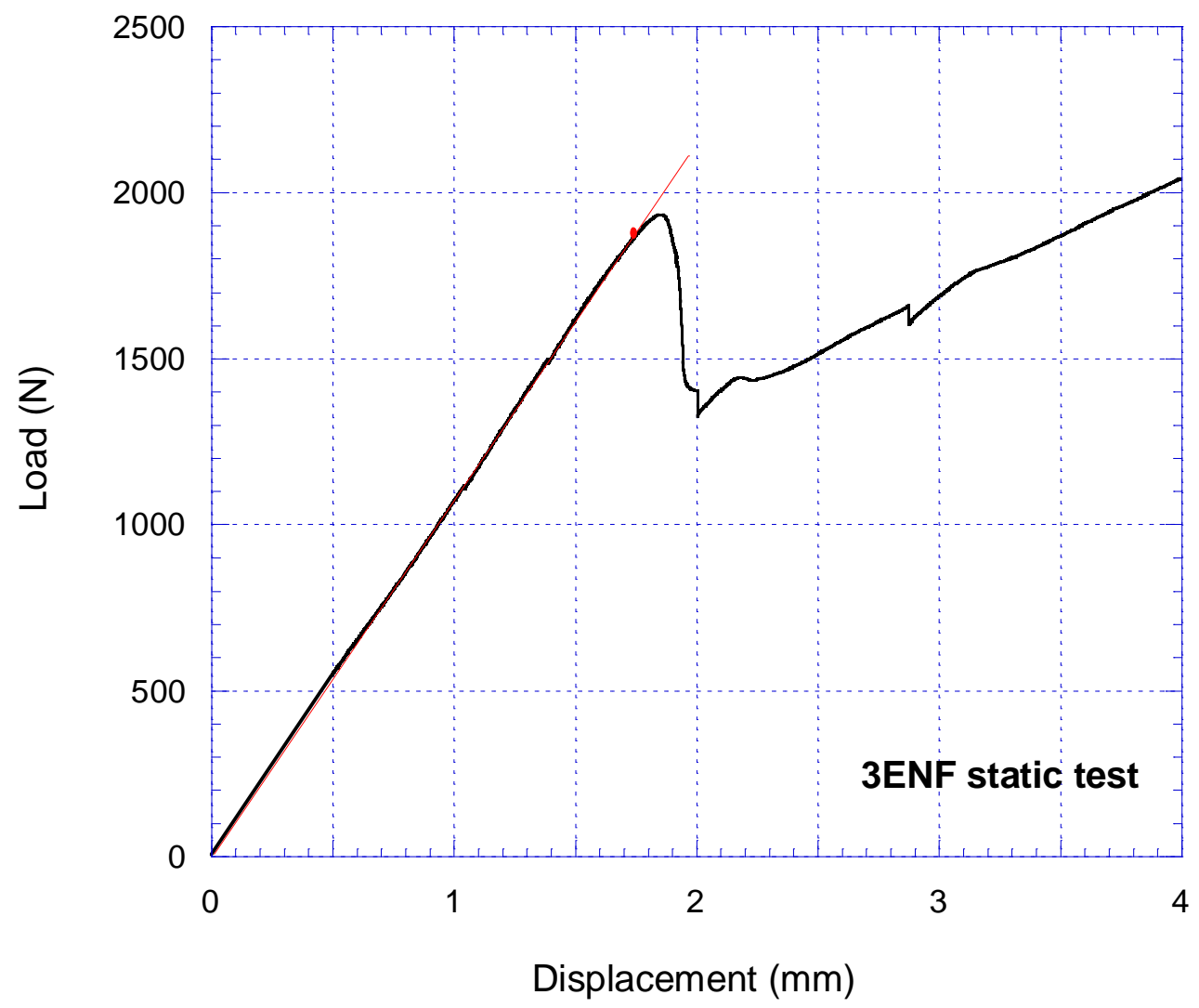

Fig. 10. Load-displacement diagram for $3 E N F$ mode II loading. $G_{\| C}=1150 \mathrm{~J} / \mathrm{m}^{2}$.

The initiation delamination fracture toughness for 3ENF test was determined from the direct beam theory (DBT) method:

$$
G_{I I C}=\frac{9 P \delta a^{2}}{2 b\left(2 L^{3}+3 a^{3}\right)}=\frac{9 P^{2} a^{2} C}{2 b\left(2 L^{3}+3 a^{3}\right)}
$$

where $\delta$ is the central deflection and $L$ the half distance between lower loading points, $C$ is the compliance and $b$ is the width of the specimen (see Figure 3) [4] [5] [48]. It should be noted that measuring the crack length in mode II is very difficult as due to the formation of microcracks inclined to the crack plane (for details see [49]). This is the reason why the results of mode II is more scattered than mode I tests.

The delamination resistance in 3ENF specimens at different crack lengths were calculated and the results of $G_{I I R}$ were plotted against the crack length as shown in Figure 11 . The equation of fitted curve to these data is:

$$
G_{I I R}=0.16212 a^{2.7739}
$$




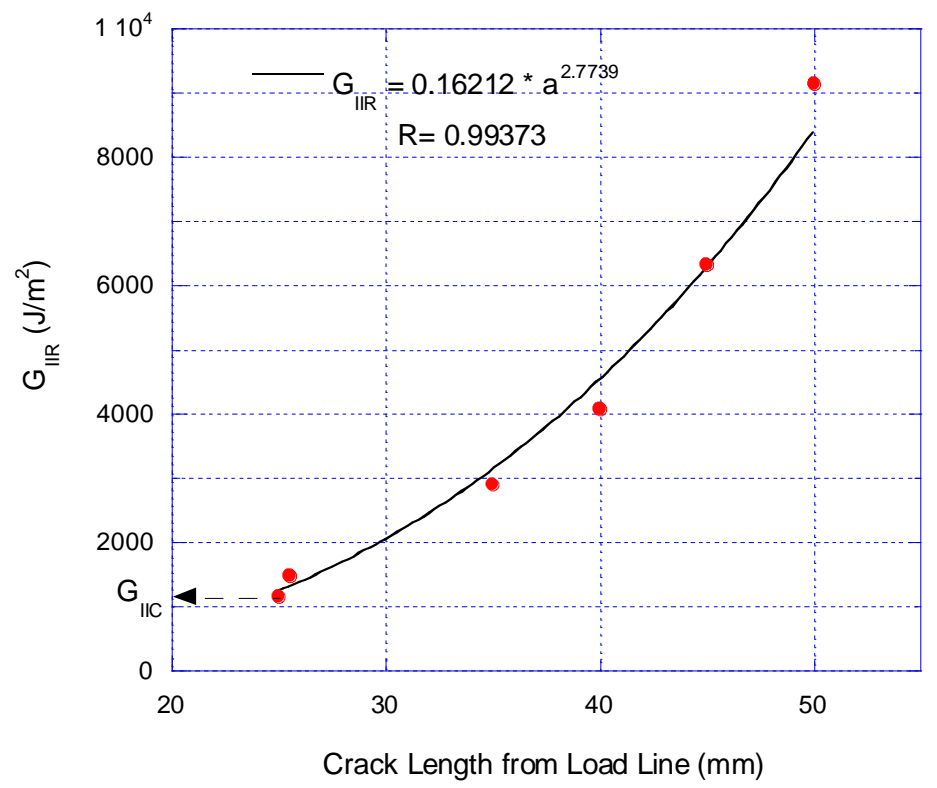

Fig. 11. Energy release rate versus delamination growth length for GFRP laminate in $\left[0_{15} / / 0_{15}\right]$ ENF test using MBT method.

\subsection{Fatigue crack propagation tests in mode II}

Delamination growth rate data was generated by performing constant displacement fatigue tests. All ENF fatigue tests were conducted at a frequency of $5 \mathrm{~Hz}$ at a displacement ratio $R=0.1$. Each ENF fatigue test was run for a predetermined number of cycles. The test was stopped, the travelling microscope was examined to measure the final crack length at the end of the loading cycle and loads and delamination lengths were recorded. When no measurable delamination propagation was observed after some interval, the load was increased. At the end of each set of $\Delta \mathrm{N}$, the test was stopped and $N, \Delta N, a, \Delta a, P_{\operatorname{Imax}}$ and $\delta_{\operatorname{lmax}}$ were recorded. From these results, $d a / d N$ was calculated. The maximum strain energy release rate, $G_{I I m a x}$, was found from DBT method in Eq. (10) and $G_{I I R}$ was calculated from Eq. (11). Finally the calculated data of $\log d a / d N$ was plotted against $\log G_{I I m a x} / G_{I I R}$ as shown in Figure 12. In this plot, the best linear curve was fitted to the experimental propagation data and the Paris' law coefficients for the GFRP in mode II were found to be $\mathrm{m}=4.0$ and $\mathrm{C}=13.49$. Therefore the $d a / d N$ equation representing region $\mathrm{II}$ crack growth is:

$$
\frac{d a}{d N}=13.49\left(\frac{G_{I I m a x}(a)}{G_{I I R}(a)}\right)^{4.0}
$$




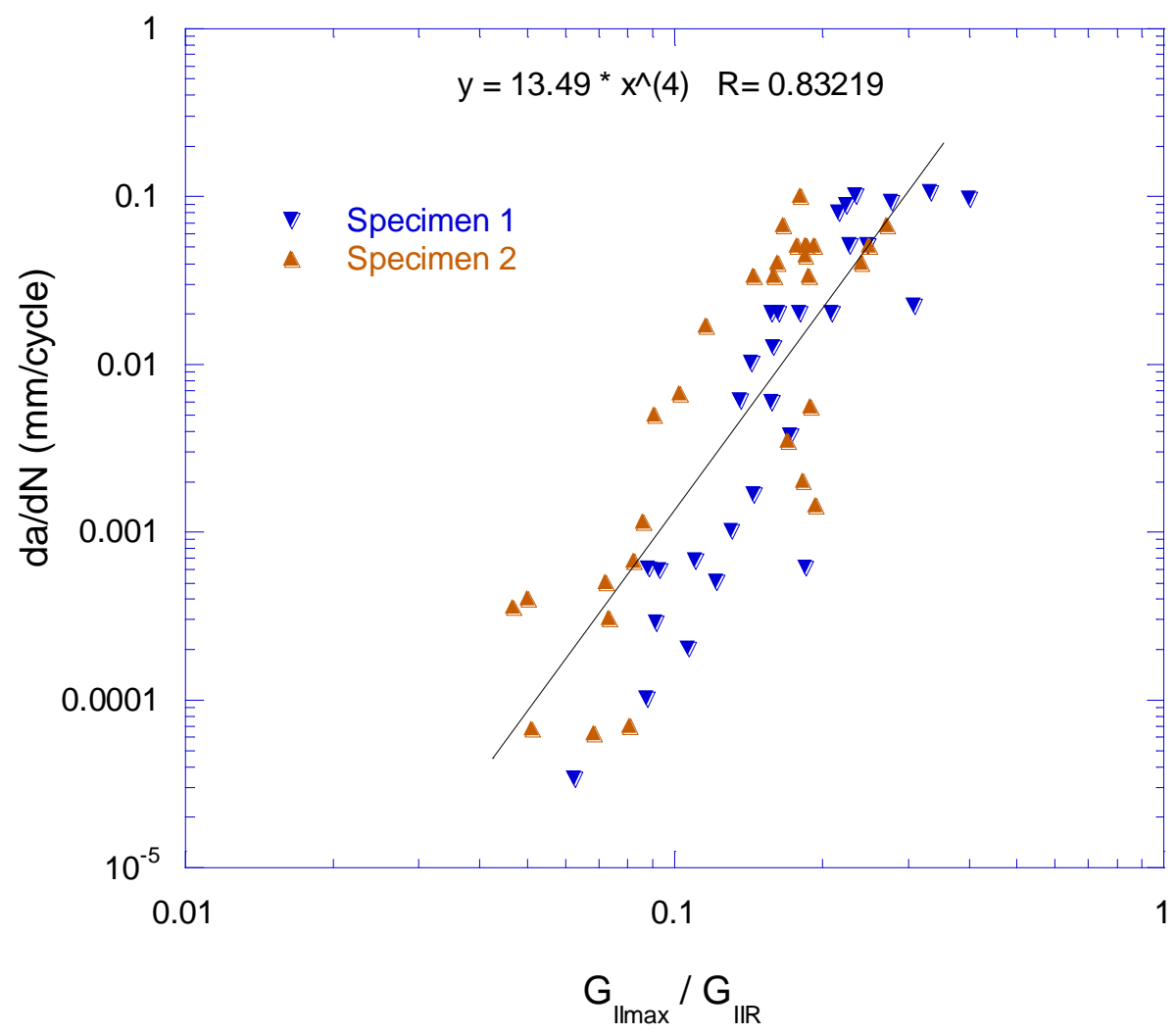

Fig. 12. Crack propagation in ENF specimens.

\subsection{Fractography analysis of fracture surface in Mode II static and fatigue tests}

A SEM fractography analysis was performed on samples of material extracted from the crack growth zone of specimens tested under mode II monotonic and cyclic loading. The samples were cut from the ENF beams, and gold-coated using a Polaron SC7640 gold sputter coater evacuated with a vacuum pump. All fracture surface analyses were performed on a ZEISS EVO 50 scanning electron microscope (SEM), operated at 20kV accelerating voltage, controlled by ZIESS software. The samples were then observed at high magnifications.

The schematic diagram in Figure 13 shows the locations of SEM images shown in Figures 1416 on fracture surfaces. The distance of SEM images from starter precrack are at about $6 \mathrm{~mm}, 12 \mathrm{~mm}$ and $18 \mathrm{~mm}$ on fracture surface at $0 / 0$ ply interface at the centre of ENF specimen after static and fatigue tests. The fracture morphology under mode II monotonic loading in Figures 14(a), 15(a) and 16(a) show fracture features such as the fibres imprints, matrix cracking, fibre breakage and shear cusps. No visible matrix remains was observed on the debonded fibres and the amount of broken matrix cusps on fracture surface are relatively small. The cusps formation is due to matrix shear cracks. These shear cracks are 
formed at low load level lower than $G_{\text {IIC }}$ [14]. However, the images of fatigued ENF surfaces in Figures 14(b), 15(b) and 16(b) show that the fibres debonded with cohesive failure of the matrix through the matrix and remains of the resin debris on the debonded fibres are visible and some polymer matrix whitening at the cohesive zone is apparent. Unlike the monotonic case, the edges of fibre imprint on the fracture surface of fatigue specimens are whiten showing plastic deformation of the matrix. In fatigue surfaces plenty number of broken resins are formed when friction between upper and lower surfaces tear the shear cusps from the fracture surface. These pieces of matrix are called as matrix rollers [14]. Also as can be seen in Figure 16, the size of matrix fragments on monotonic loading surfaces is many times bigger than those of fatigue fracture surfaces. In both monotonic and fatigue fracture surfaces the typical fibre bridging as well as broken fibres are also observed. Shindo et al. [13] reported similar fracture surface and Landry et al. [15] also experienced resin debris on the fracture surface of the fatigued ENF specimens. The conclusion is that fibre/matrix interface decohesion and formation of shear cusp and pull off of shear cusps during the fatigue test play major role on delamination growth mechanism in Mode II. The SEM images of fracture surface in ENF fatigue tests revealed resin debris as a dominant feature also reported by other researchers [50].

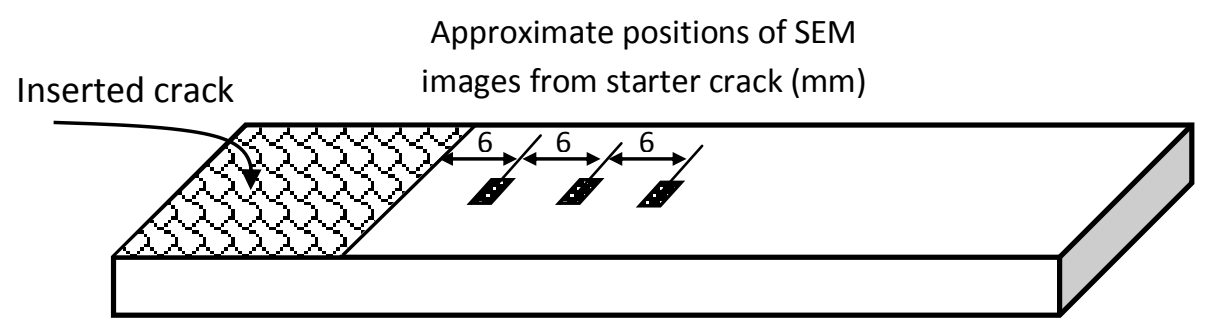

Fig. 13. Schematic diagram showing the position of SEM images shown in Figures 14-16 on fracture surface at $0 / 0$ ply interface at the centre of ENF specimen after static and fatigue tests relative to starter precrack. 


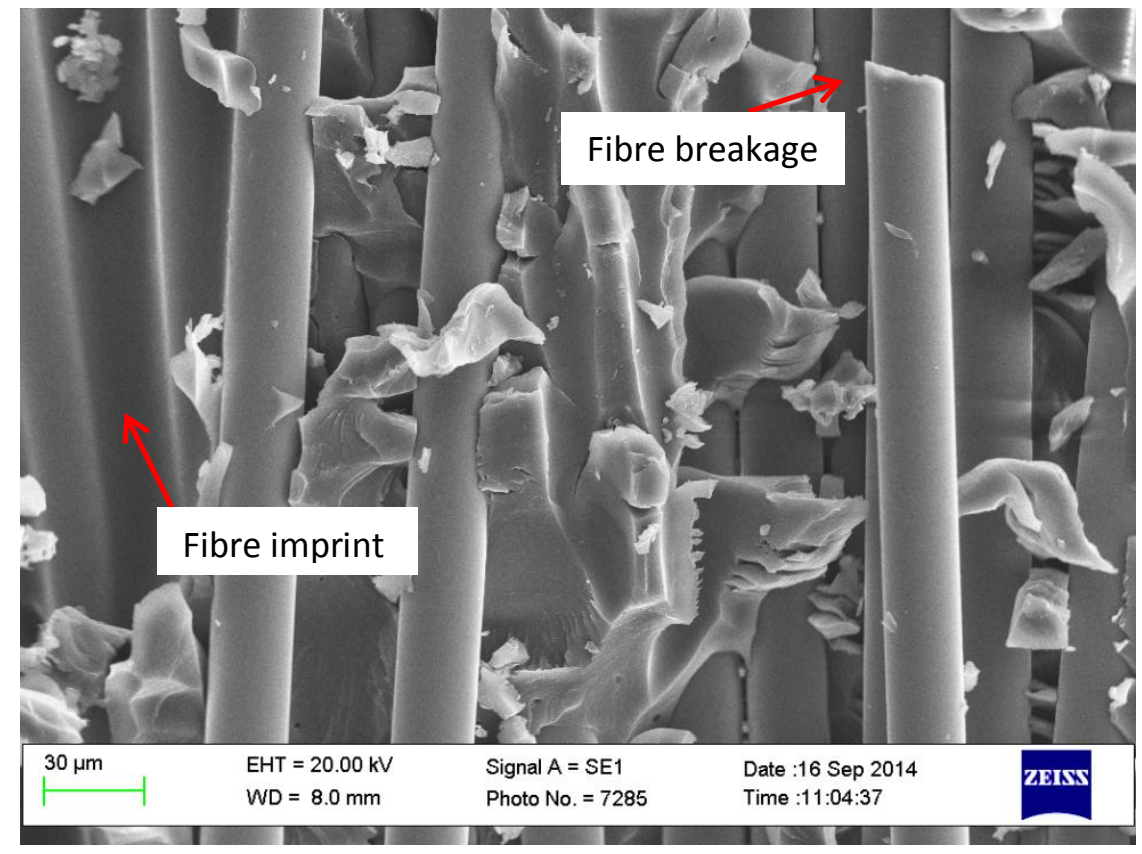

(a) Static at crack advance of $6 \mathrm{~mm}$

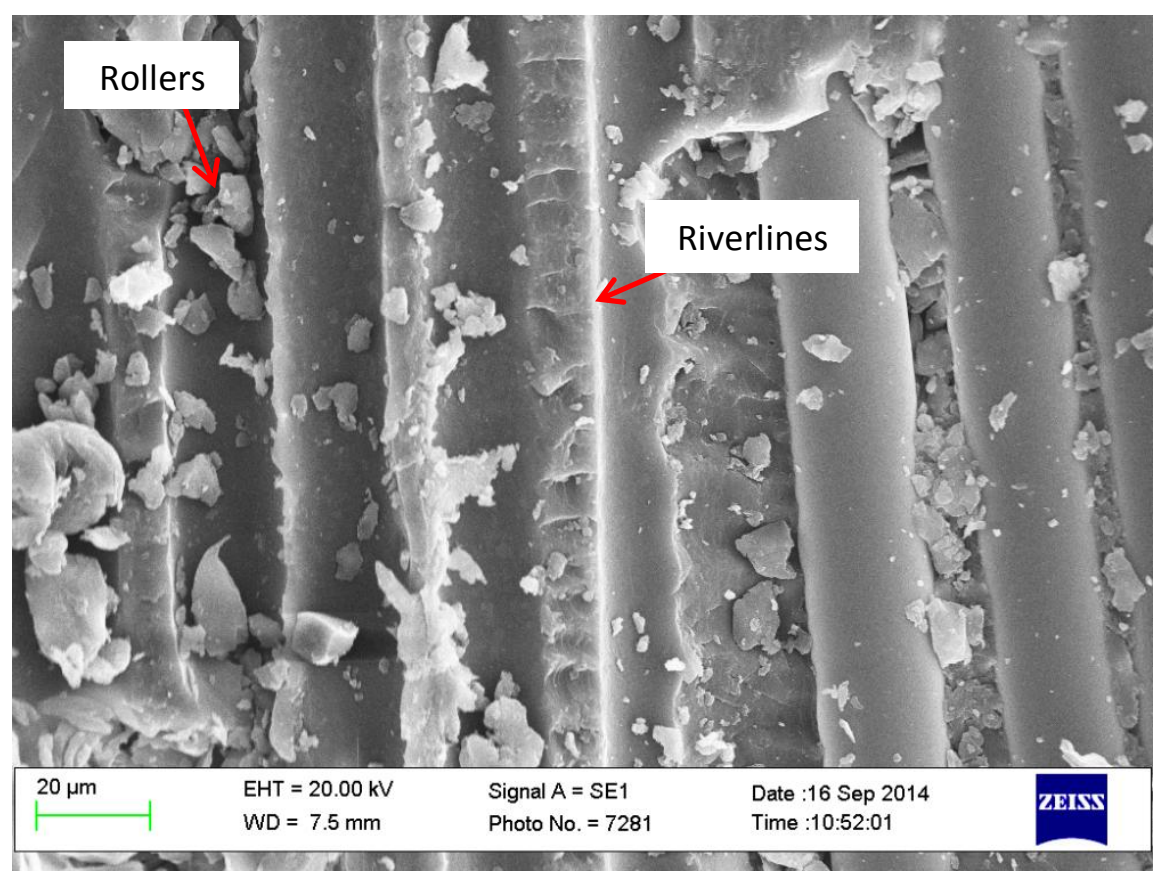

(b) Fatigue at crack advance of $6 \mathrm{~mm}$

Fig. 14. High magnification SEM images of fracture surface after $6 \mathrm{~mm}$ crack advance generated at $0 / 0$ ply interface at the centre of ENF specimen in static and fatigue tests (direction of delamination from top to bottom). 


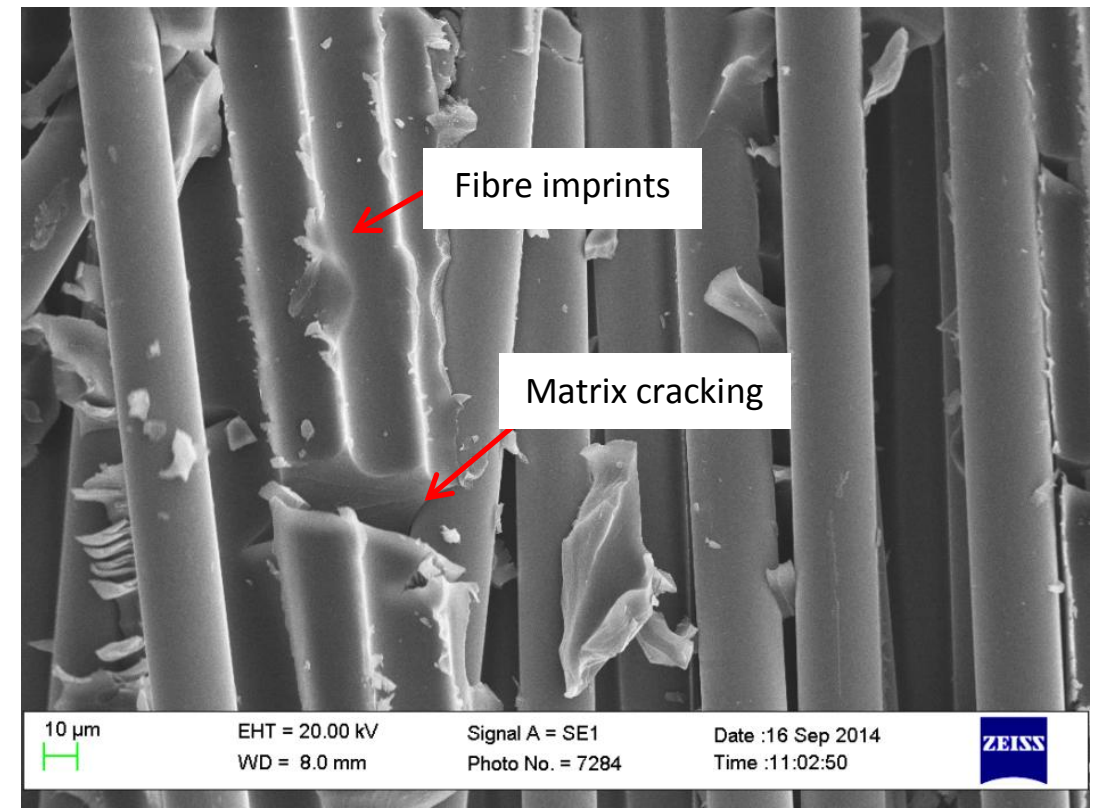

(a) Static at crack advance of $12 \mathrm{~mm}$

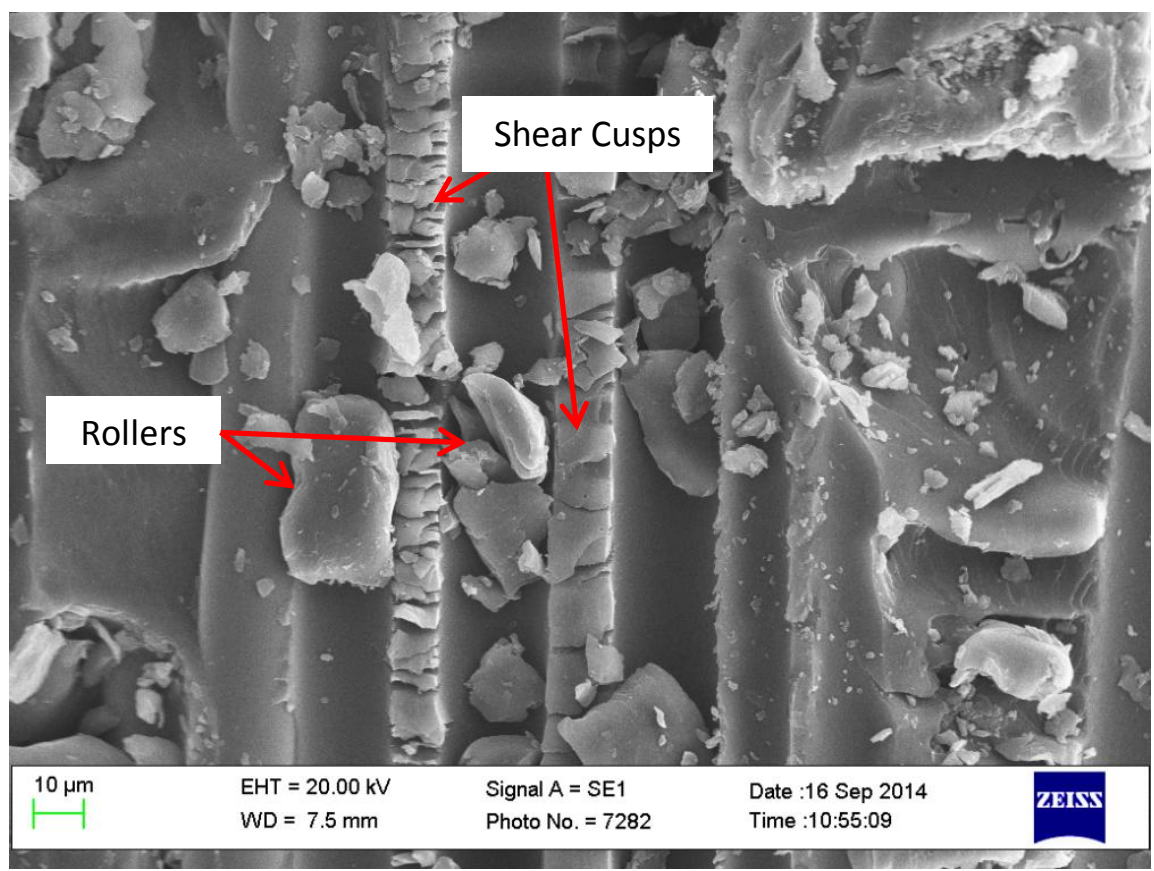

(b) Fatigue at crack advance of $12 \mathrm{~mm}$

Fig. 15. Comparison of SEM images of fracture surface after $12 \mathrm{~mm}$ crack advance generated at $0 / 0$ ply interface at the centre of ENF specimen in static and fatigue tests (direction of delamination from top to bottom). 


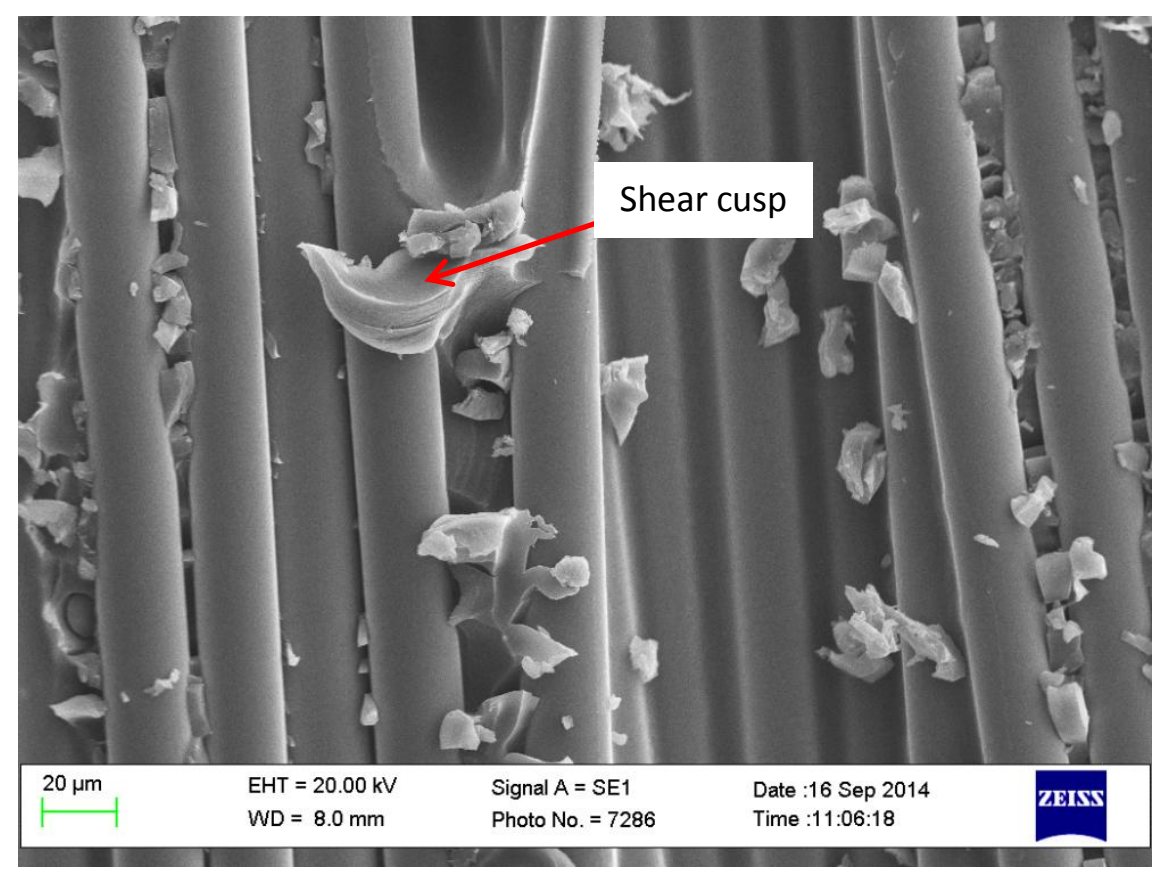

(a) Static at crack advance of $18 \mathrm{~mm}$

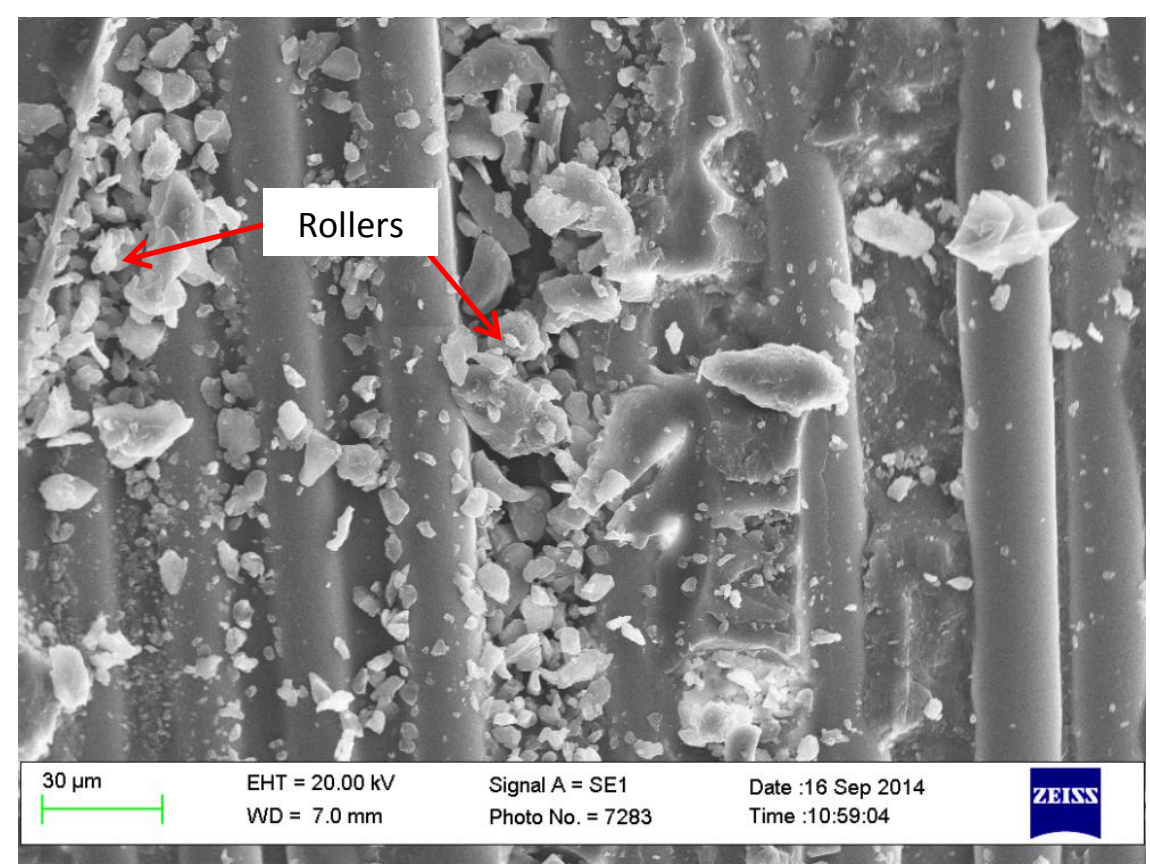

(b) Fatigue at crack advance of $18 \mathrm{~mm}$

Fig. 16. Comparison of SEM images of fracture surface after $18 \mathrm{~mm}$ crack advance generated at 0/0 ply interface at the centre of ENF specimen in static and fatigue tests (direction of delamination from top to bottom). 


\section{Conclusions}

In this paper different aspects of delamination propagation of GFRP under cyclic loading were investigated. Firstly the onset life test for $0 / / 0$ interface of GRFP laminate in mode I loading was performed using DCB specimens. The mode I threshold stain energy release rate, $G_{I t h}$, from the onset life test at $\mathrm{N}=10^{7}$ was determined to be $0.15 G_{I C}$. Further from the equation of fitted curve to mode I experimental propagation data, the Paris' law coefficient for the laminated GFRP in mode I was determined at $m=5.27$ and $C=4.47 \times 10^{-2}$.

Secondly the mode II fatigue crack growth at $0 / / 0$ interface of GFRP laminate was investigated using $3 E N F$ specimens. In this mode also the fatigue propagation behaviour is described by Paris' law as a function of energy release rate in mode II loading. From the fitted curve to mode II experimental propagation data, the Paris' law coefficient for the laminated GFRP in mode II was determined at $\mathrm{m}=4.0$ and $\mathrm{C}=13.49$.

The fractography images of fracture surfaces of mode II monotonic ENF tests show that the fibres are debonded at interface with no visible matrix remains on the debonded fibres being observed and some matrix debris created from shear cusps. However, the images of fatigue surfaces show that the fibres debonded cohesively through the matrix and remains of the matrix on the debonded fibres and whitening of polymer matrix especially around the edges of fibre imprints are visible. Also the size of matrix fragments on monotonic loading is many times bigger than those on failed fracture surface under cyclic loading, though their numbers are less. In both monotonic and fatigue surfaces the typical fibre bridging as well as broken fibres can be observed. The conclusion is that fibre/matrix interface decohesion and formation of shear cusp and pull off of shear cusps during the fatigue test play major role on delamination growth mechanism in Mode II.

\section{Acknowledgement}

The authors would like to thank technicians at School of Mechanical \& Automotive Engineering in Kingston University: Alex Vine and Dean Wells for helping in various mechanical testing, and Richard Giddens for SEM analysis. 


\section{References}

[1] US Department of Defense, "The Composite Materials Handbook, MIL-17 Mil-HDBK-17-1F," USA, January 1997.

[2] J. G. Williams, "On the Calculation of Energy Release Rates for Cracked Laminates," Int. J. Fract., vol. 36 , no. 2, pp. 101-119, 1988.

[3] J. G. Williams, "The fracture mechanics of delamination tests," Journal of Strain Analysis, vol. 24, no. 4, pp. 207-214, 1989.

[4] S. Hashemi, A. J. Kinloch and J. G. Williams, "The analysis of interlaminar fracture in uniaxial fibre-polymer composites," Proc Roy Soc London A, vol. 427, pp. 173-99, 1990.

[5] Y. Wang and J. G. Williams, "Corrections for Mode II Fracture Toughness Specimens of Composite Materials," Compos. Sci. Technol., vol. 43, no. 3, pp. 251-256, 1992.

[6] K. Shivakumar, H. Chen, F. Abali, D. Le and C. Davis, "A total fatigue life model for mode I delaminated composite laminates," International Journal of Fatigue, vol. 28, pp. 33-42, 2006.

[7] M. Hojo, S. Matuda, M. Tanaka, S. Ochiai and A. Murakami, " Mode I delamination fatigue properties of interlayer-toughened CF/epoxy laminates," Composites science and technology, vol. 66, pp. 665-675, 2006.

[8] M. Hojo, K. Nakashima, T. Kusaka, M. Tanaka, T. Adachi, T. Fukuoka and M. Ishibashi, "Mode I fatigue delamination of Zanchor-reinforced CF/epoxy laminates," International journal of fatigue, vol. 32, pp. 37-45, 2010.

[9] F. Pegorin, K. Pingkarawat and A. P. Mouritz, "Comparative study of the mode I and mode II delamination fatigue properties of z-pinned aircraft composites," Materials \& Design, vol. 65, p. 139-146, 2015.

[10] M. Arai, Y. Noro, K. Sugimoto and M. Endo, " Mode I and mode II interlaminar fracture toughness of CFRP laminates toughened by carbon nanofiber interlayer," Composites Science and Technology, vol. 68, pp. 516-525, 2008.

[11] P. Coronado, A. Argüelles, A. Viña, V. Mollón and I. Viña, "Influence of temperature on a carbon-fibre epoxy composite subjected to static and fatigue loading under mode-I delamination," International Journal of Solids and Structures, vol. 49, pp. 2934-2940, 2012.

[12] M. Hojo, T. Ando, M. Tanaka, T. Adachi, S. Ochiai and Y. Endo, "Mode I and II interlaminer fracture toughness and fatigue delamination of CF/epoxy laminates with self-same epoxy interleaf," International journal of fatigue, vol. 28, pp. 1154-1165, 2006.

[13] Y. Shindo, T. Takeda, F. Narita, N. Saito, S. Watanabe and K. Sanada, "Delamination growth 
mechanisms in woven glass fiber reinforced polymer composite under Mode II fatigue loading at cryogenic temperatures," Composites science and technology, vol. 69, pp. 1904-11, 2009.

[14] L. Asp, A. Sjögren and E. Greenhalgh, "Delamination growth and thresholds in a carbon/epoxy composite under fatigue loading," J Comp Tech Res, vol. 23, no. 2, p. 55-68, 2001.

[15] B. Landry, G. LaPlante and L. LeBlanc, "Environmental effect on mode II fatigue delamination growth in an aerospace grade carbon/epoxy composite," Composites: Part A, vol. 43, pp. 475485, 2012.

[16] V. Fernandez, M. F. S. F. de Moura, L. F. M. da Silva and T. Marques, "Characterization of composite bonded joints under pure mode II fatigue loading," Composite structures, vol. 95, pp. 222-226, 2013.

[17] C. Rans, R. C. Alderliesten and R. Benedictus, "Misinterpreting the results: How similitude can improve our understanding of fatigue delamination growth," Composites Science and Technology, vol. 71 , pp. 230-238, 2011.

[18] S. Stelzer, A. J. Brunner, A. Argüelles, N. Murphy, G. M. Cano and G. Pinter, “Mode I delamination fatigue crack growth in unidirectional fiber reinforced composites: Results from ESIS TC4 round-robins," Engineering Fracture Mechanics, vol. 116 , pp. 92-107, 2014.

[19] F. Aymerich, R. Onnis and P. Priolo, "Analysis of the effect of stitching on the fatigue strength of single-lap composite joints," Compos Sci Technol, vol. 66, no. 2, pp. 166-75, 2006.

[20] M. Beghini, L. Bertini and P. Forte, "Experimental investigation on the influence of crack front to fiber orientation on fatigue delamination growth rate under mode II," Compos Sci Technol, vol. 66 , no. 2, p. 240-247, 2006.

[21] A. J. Russell and K. N. Street, "The Effect of Matrix Toughness on Delamination: Static and Fatigue Fracture under Mode II Shear Loading of Graphite Fiber Composites," Toughened Composites," in ASTM STP 937, N. J. Johnston, Ed., 1987, pp. 275-294.

[22] M. N. Bureau, F. Perrin, J. Denault and J. Dickson, "Interlaminar fatigue crack propagation in continuous glass fiber/polypropylene composites," Int J Fatigue, vol. 24, no. 2-4, pp. 99-108, 2002.

[23] D. Wilkins, J. Eisenmann, R. Camin, W. Margolis and R. Benson, "Characterizing delamination growth in graphite-epoxy," in Damage in composite materials, K. Reifsnider, Ed., ASTM STP 775 American Society for Testing and Materials, 1982, pp. 168-83.

[24] R. C. Alderliesten, "On the Evaluation of Delamination Resistance in Composites," in 9th International Conference of Composite Science and Technolog (ICCST/9), 2020 Scientific and Industrial Challenges, Naples, ITALY, 2013.

[25] L. Yao, R. Alderliesten, M. Zhao and R. Benedictus, "Discussion on the use of the strain energy 
release rate for fatigue delamination characterization," Composites: Part A, vol. 66, pp. 65-72, 2014.

[26] R. Jones, S. Pitt, D. Hui and A. Brunner, "Fatigue crack growth in nano-composites," Composite Structures, vol. 99, pp. 375-379, 2013.

[27] A. Russell and K. Street, "Predicting interlaminar fatigue crack growth rate in compressively loaded laminates, in: P.A. Lagace (Ed.), Composite materials: fatigue and fracture," in ASTM STP 1012, vol. 2nd Vol., Philadelphia, 1989, pp. 162-78.

[28] G. Allegri and M. R. Wisnom, "A non-linear damage evolution model for mode II fatigue delamination onset and growth," Int J Fatigue, vol. 43, pp. 226-34, 2012.

[29] N. Blanco, E. K. Gamstedt, L. E. Asp and J. Costa, "Mixed-mode delamination growth in carbonfibre composite laminates under cyclic loading," Int J Solids Struct, vol. 41, no. 15, pp. 4219-35, 2004.

[30] A. Poursartip, "The characterization of edge delamination growth in laminates under fatigue loading," in Toughened composites, ASTM STP 937, N. J. Johnston, Ed., Philadelphia, American Society for Testing and Materials, 1987, pp. 222-41.

[31] G. B. Murri, "Evaluation of delamination onset and growth characterization methods under mode I fatigue loading," in ASC 27th Technical Conference-15th US-Japan Conference on Composites, Arlington, TX, October 1-3, 2012.

[32] H. Chen, K. Shivakumar and F. Abali, "A comparison of total fatigue life models for composite laminates," Fatigue Fract Engng Mater Struct, vol. 29, no. 1, pp. 31-39, 2006.

[33] L. Peng, J. Zhang, L. Zhao, R. Bao, H. Yang and B. Fei, "Mode I delamination growth of multidirectional composite laminates under fatigue loading," J Compos Mater, vol. 45, no. 10, pp. 1077-90, 2011.

[34] A. Wang, M. Slomiana and R. Bucinell, "Delamination crack growth in composite laminates," in Delamination and debonding of materials, ASTM STP 876, W. Johnson, Ed., Philadelphia, American Society for Testing and Materials, 1985, pp. 135-67.

[35] A. J. Russell and K. N. Street, "The Effect of Matrix Toughness on Delamination: Static and Fatigue Fracture under Mode II Shear Loading of Graphite Fiber Composites," Toughened Composites," in ASTM STP 937, N. J. Johnston, Ed., Philadelphia, American Society for Testing and Materials, 1987, pp. 275-294.

[36] X. X. Xu, A. D. Crocombe and P. A. Smith, "Mixed-mode fatigue and fracture behaviour of joints bonded with either filled or filled and toughened adhesive," Int J Fatigue, vol. 17, no. 4, pp. 27986, 1995.

[37] M. M. Shokrieha, M. Heidari-Rarania and M. Ayatollahi, "Delamination R-curve as a material 
property of unidirectional glass/epoxy composites," Materials \& Design, vol. 34, p. 211-218, 2012.

[38] M. M. Shokrieh, M. Salamat-talab and M. Heidari-Rarani, "Effect of initial crack length on the measured bridging law of unidirectional E-glass/epoxy double cantilever beam specimens," Materials \& Design, vol. 55, pp. 605-611, 2014.

[39] S. Giannis, K. Hansen and R. H. Martin, "Accounting for the R-curve effects on the mode I fatigue delamination growth characterisation of unidirectional composites," in 5th Annual technical conference of the american society for composites, Ohio, Dayton, Ohio, 2010.

[40] R. C. Alderliesten, "Critical review on the evaluation of delamination resistance in composites," in 9th International conference on composite science and technology, 2013.

[41] R. H. Martin and G. B. Murri, "Characterization of mode I and mode II delamination growth and thresholds in AS4/PEEK composites," in ASTM STP1059, Composite materials: testing and design, vol. 9, S. Garbo, Ed., Philadelphia, American Society for Testing and Materials, 1990, pp. 251-70.

[42] A. J. Curley, H. Hadavinia, A. J. Kinloch and A. C. Taylor, "Predicting the service-life of adhesivelybonded joints," Int J Fract, vol. 103, no. 1, pp. 41-69, 2000.

[43] M. M. Abdel Wahab, I. A. Ashcroft, A. D. Crocombe and P. A. Smith, "Numerical prediction of fatigue crack propagation lifetime in adhesively bonded structures," Int J Fatigue, vol. 24, no. 6, pp. 705-9., 2002.

[44] G. E. P. Box and R. D. Norman, Empirical Model-Building and Response Surfaces, p. 424, Wiley, 1987.

[45] J. G. Williams, "End corrections for orthotropic DCB specimens," Compos Sci Technol, vol. 35, pp. 367-76, 1989.

[46] S. Hashemi, A. J. Kinloch and J. G. Williams, "Corrections Needed in Double-cantilever Beam Tests for Assessing the Interlaminar Failure of Fibre-Composites," Journal of Materials Science Letters, vol. 8, pp. 125-129, 1989.

[47] T. O'Brien, "Towards a damage tolerance philosophy for composite materials and structures," in Composite materials: Testing and design. Proceedings of the 9th Symposium , Philadelphia, PA, 1990.

[48] A. J. Russell and K. N. Street, "Factors Affecting the Interlaminar Fracture Energy of Graphite/Epoxy Laminates," in Progress in Science and Engineering of Composites, ICCM-IV, Japan Society for Composite Materials, Tokyo, 1982.

[49] B. R. K. Blackman, A. J. Kinloch and M. Paraschi, "The determination of the mode II adhesive fracture resistance, GIIC, of structural adhesive joints: an effective crack length approach," 
Engineering Fracture Mechanics, vol. 72, pp. 877-897, 2005.

[50] M. Gilchrist and N. Svensson, "A fractographic analysis of delamination within multidirectional carbon/epoxy laminates," Comp Sci Tech, vol. 55, pp. 195-207, 1995. 